\title{
الصناعة المصرفية واثر السياسة النقدية على تحقيق الاستقرار الاقتصادي في ظل هسار التمرير المالي
}

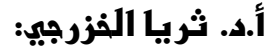

م. ياسهين العيالي

الإقدهة

ترجع ظاهرة زيادة التحرير المالي التي سادت الاقتصـاد العـالمي المعاصر الى هيمنـة كل من العولمـة و الليبر اليـة

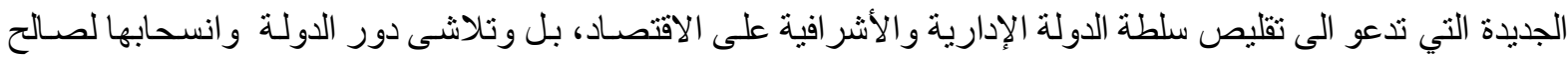

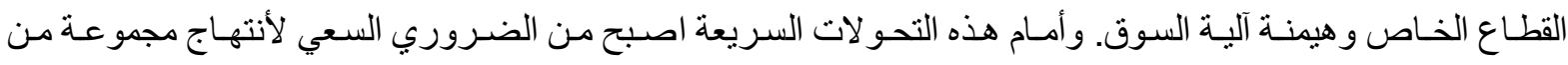

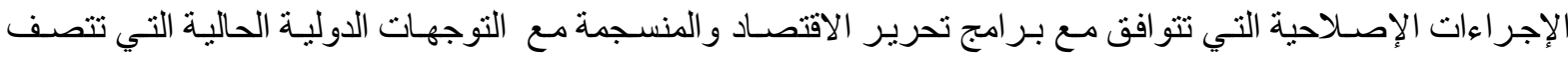

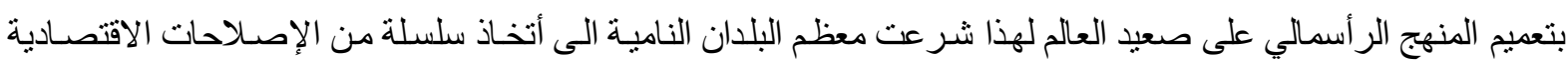
و المالية بهدف الانتقال من الاقتصاد المركزي الى الاقتصـاد الحر. لذا ينبغي هنـا ان نتعرف على ماهية التحرير المسالي، وما هي وما هي مبرر اته، وما هي أدواته واساليبه، وشروط نجاحه، هذا ما سنحاول التطرق اليه في هذا البحث الهية البحث: ان الانتقال باتجاه اقتصاد السوق ينطلب دور اكبر للقطاع الخـاص في الاقتصـاد الوطني وفي عملية التنمية الاقتصـادية بالاعنمـاد على المبـادرة الفرديـة وهذا يتطلب بالضـرورة تعبئة المسخرات الوطنيـة ومـن ثم تـوفير الائتمـان بالحجم و الكلفة المناسبين له من اجل تحقيق دورة الريادي في الاقتصـاد بعد ان كان هذا الدور منوط بالقطاع العام في ظل

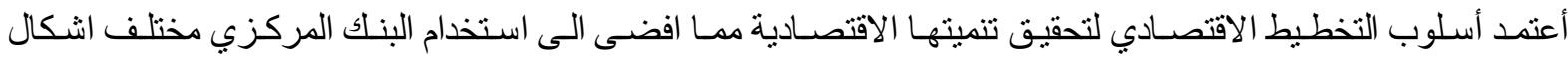

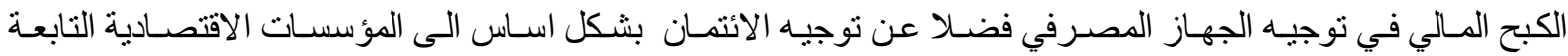

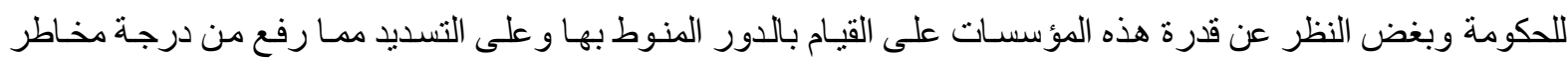
الايتمان و الديون المعدومة او المشكوك في تحصيالها، وقد عمل البنك المركزي على استخدام اسلوب تحديد سقوف لسعر

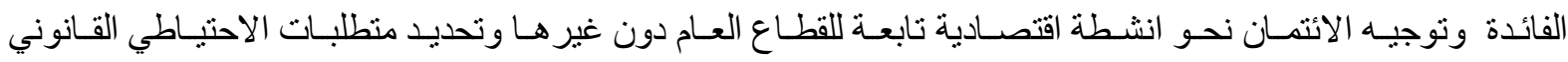

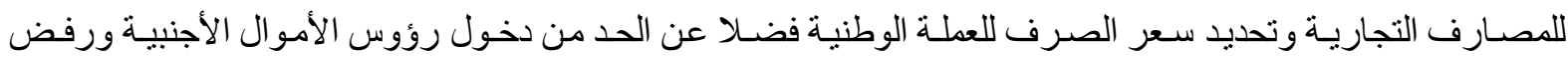

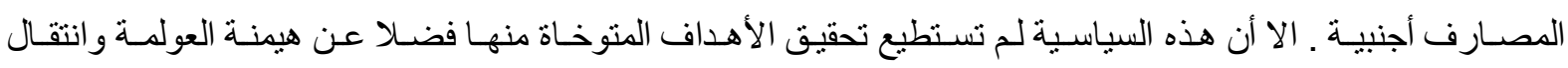

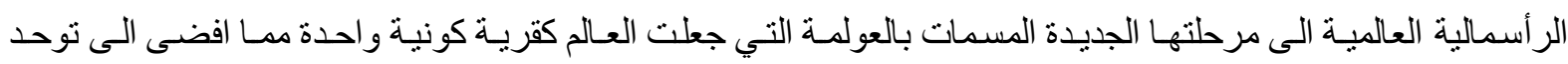

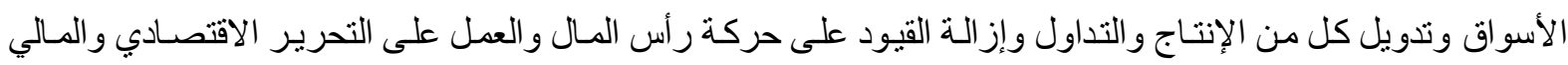
في ظل منظمة التجارة العالمية أن هيمنـة هذه السياسـة دفع العديد من البلدان الناميـة الى الانتقال من سياسية الكبح المـالي

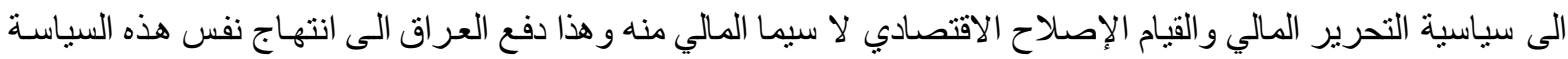

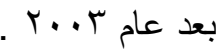

مشكلة البحث: من اجل انتقال اقتصـاد من سياسـه اقتصـاديه الى نقيضهـا وبشكل قابل للنجاح لا يعتمد بالضرورة على

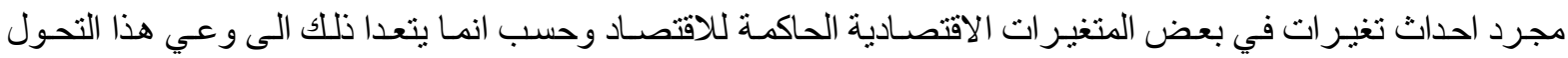
وتو افر ستر اتيجية ملائمسه تستند الى سياسـه اقتصـادية كلية وسياسـات جزئية تعي الاهداف الواجب تحقبقها لخدم عمليـة

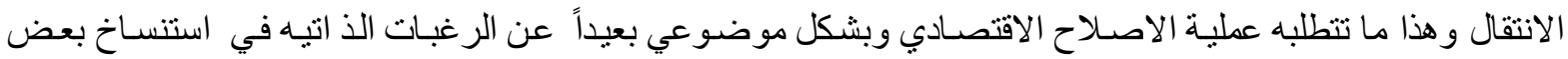

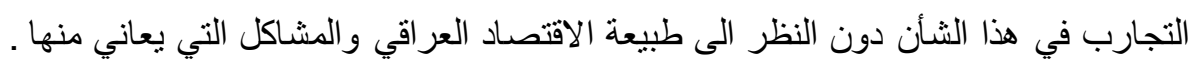


هدف البحث: يهدف البحث الى التعرف على طبيعة الصناعة المصرفية في العراق ومدى امكانية نجاح سياسـة التحرير

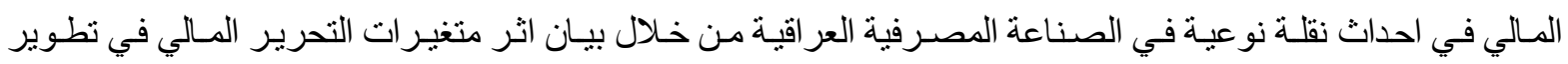

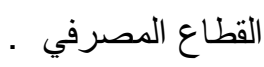

فرضية البحث: ان الانتقال من سياسـ اقتصادية الى نقيضها يتطلب في كثير من الاحيان احداث تغيرات جذريه سواء

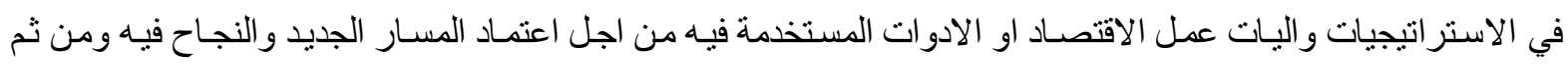

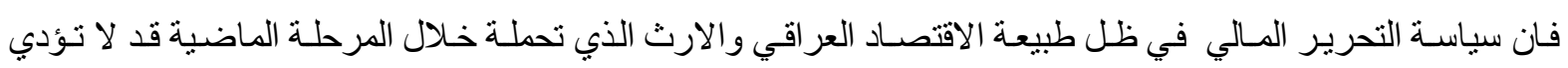

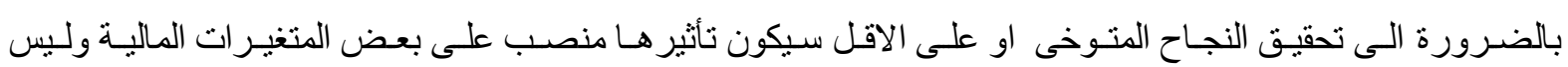

جميعها. منهجية البحث: سيتم الاعتماد على منهج التحليل الاستدلالي للوصول الى فرضية البحث بالانتقال من العام وصو لا الى

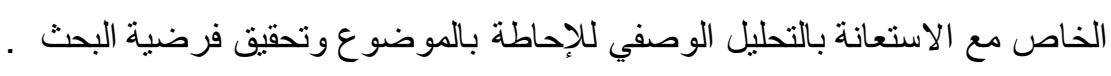

\section{المبحث الاول - طبيعة الصناعة المصرفية في العراق في ظل الكبح المالي:}

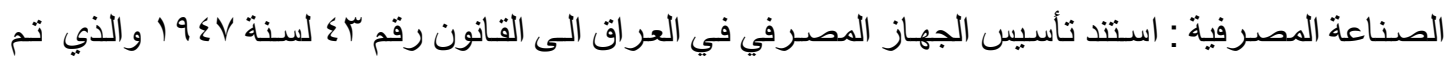
بموجبة تأسس المصرف الوطني العر اقي وقد تم في ضو ء ذلك فلك ارتباط الدينار العر اقي بالجنيه الاسترليني واعتمـاد الذهب و العملات الاجنبية و السندات الحكوميـة كغطاء للدينار ، ويعد هذا المصرف نوفئ فواة تأسيس البنك المركزي العر اقي

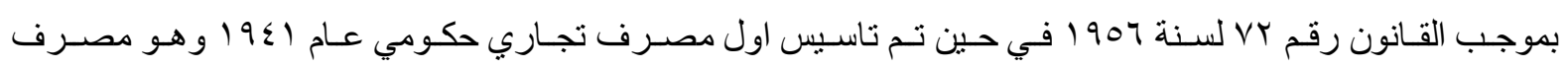

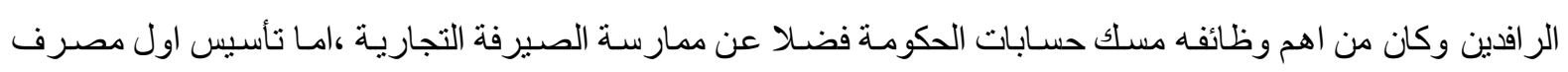

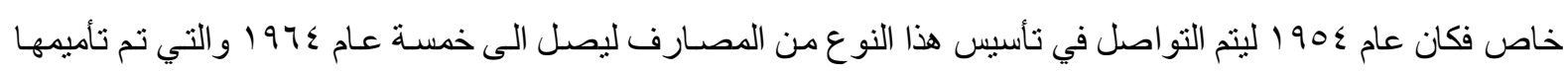

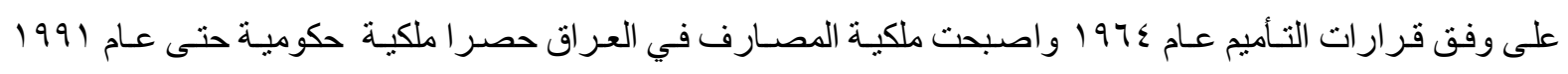
حين صدور للقانون رقم با لسنة (9919 الذي سمح بتأسيس المصسارف الخاصـة وعلى ايـة حسال يتكون الجهاز المصرفي

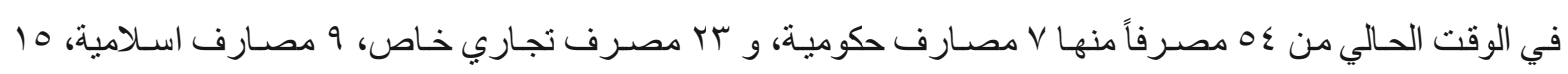

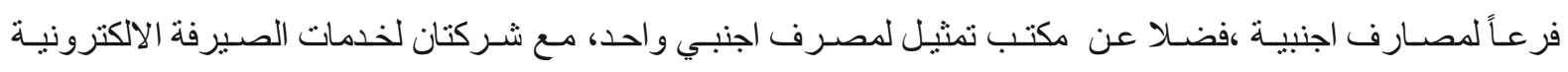

والبطاقة الذكية ( ) (1).

ان زيادة قدرة القطاع الخـاص على زيادة حجم الاستثمار ات ومن ثم احتلال مكانهـه ريادي مرموقه في عملية التنمية الاقتصادية يتطلب نو افر نظام مصرفي قادر على حشد الموارد المالية المتواجدة لدى المدخرين بكفاءة عاليـة ، الا

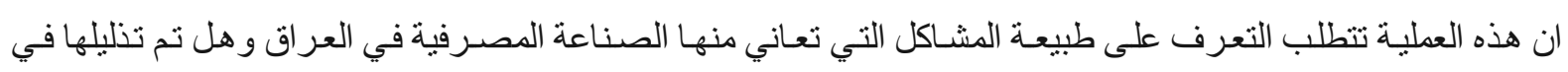

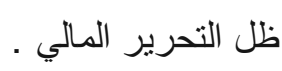

كما هو معلوم خضع القطاع المالي و المصرفي في العراق قبل عام ؟ . . ب الى سياسـة الكبح المسالي التي تضمنت

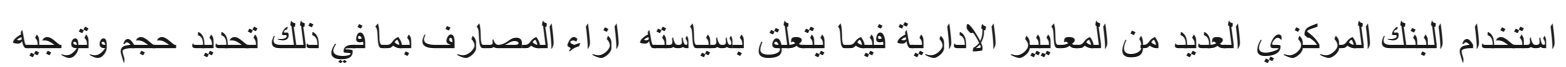

محمل صالح ، مظهز : السياسة النقاية للبنك المركزي ومتظلبات الاستقرار والنمو الاقتصادي .

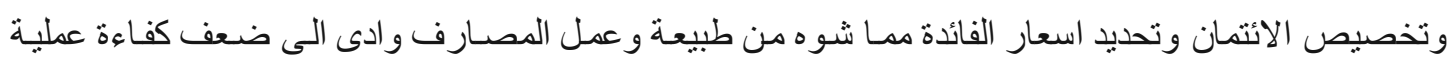

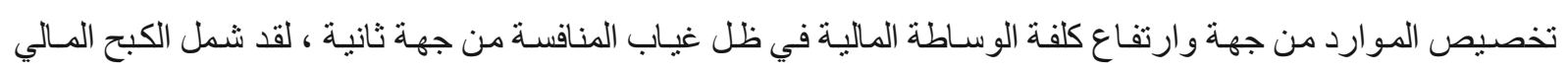


تحديد سعر الفائدة دون الاخذ بنظر الاعتبار درجة المخـاطر التي تتعرض لها العملية الائتمانية وقدرة هذه الاسعار في

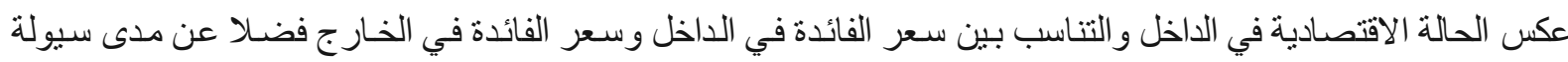

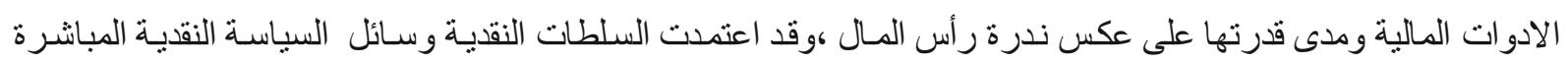
للتحكم بالمصارف ، وكان البنك المركزي خاضع لإر ادة وزارة المالية ومهيته الاساسية تنقيد عو ائد النفط وخلق النقود

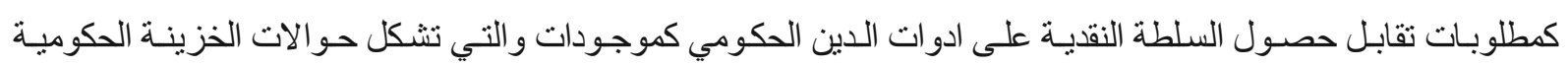

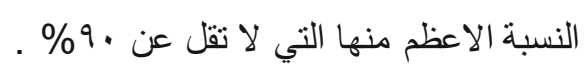

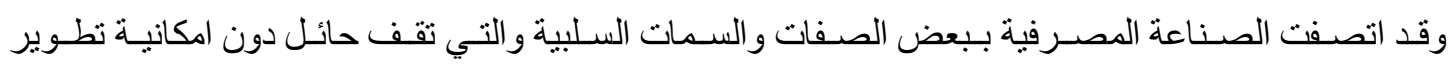

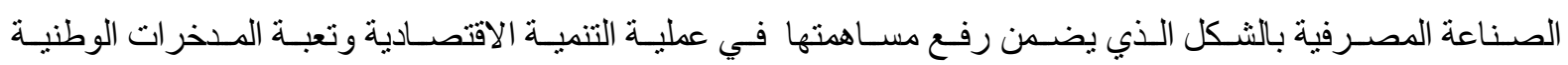

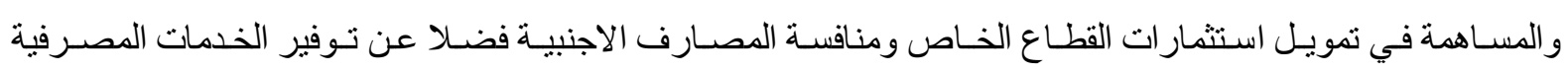
للاقتصاد العر اقي تبعا لأحدث التكنولوجية المستخدمة في هذا المجال وسنورد هنا اهم هذه الصفات:

ا - الخلل في بنية هيكل الصناعة المصرفية لاز زال القطاع العام يستحوذ على ( 99\% ) من النشـاط المصرفي مـع

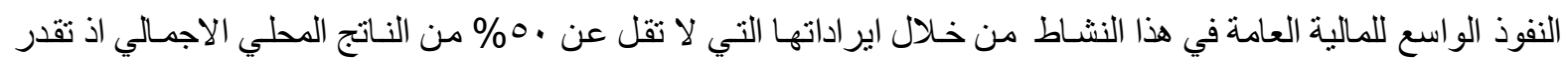

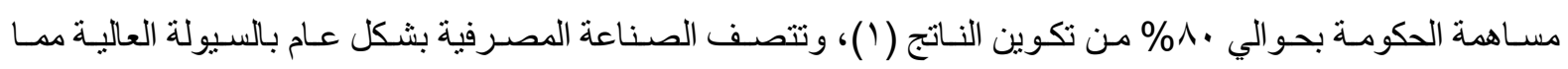
يعكس تدني رغبة المصسارف على منح الأتنمان النقدي ممـا تسبب في انخفاض درجة العمق المالي، اذ لا تتعدى نسبة

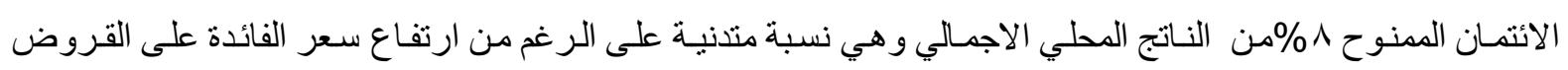

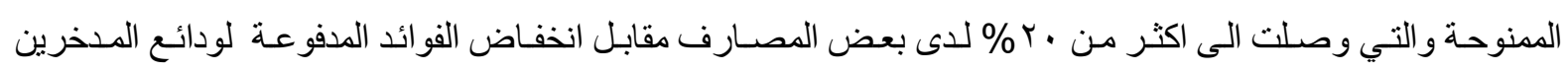

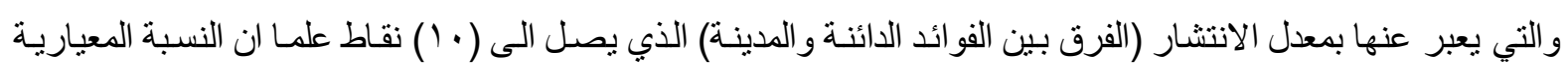

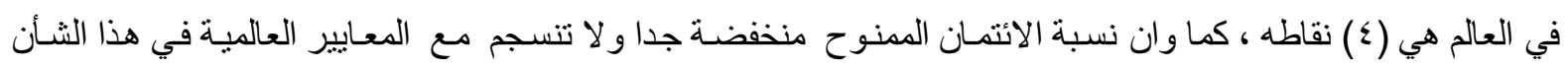

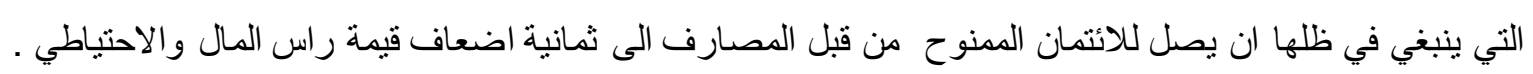

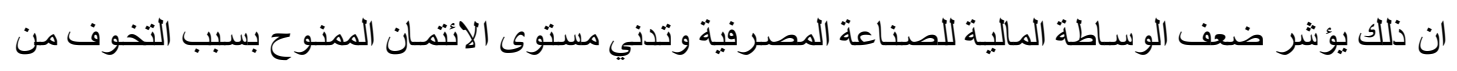

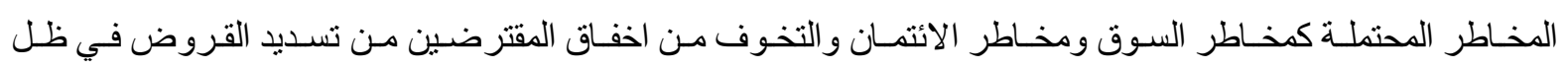

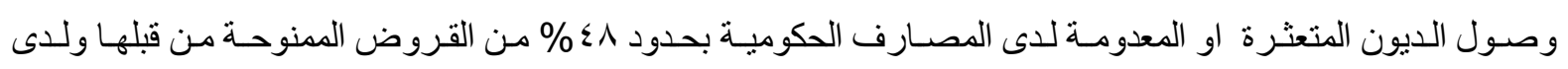

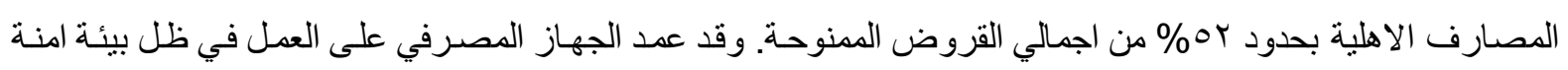


r - على الرغم من كون معظم راس المـال المصرفي يعود الى القطاع الخـاص وبنسبة تجاوز

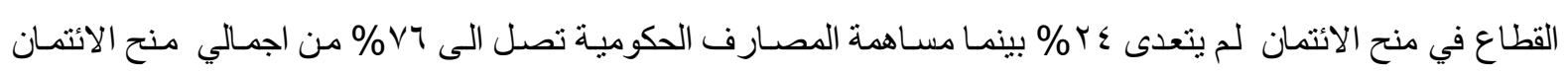

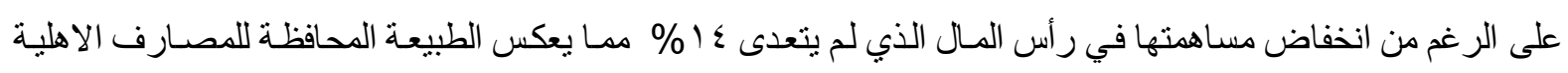

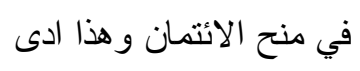

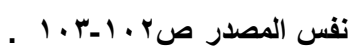

الى ارتفاع معدلات وحجم السيولة لديها والتي بلغت اكثر من •^^\% في حين النسبة المعياريـة المتعـارف

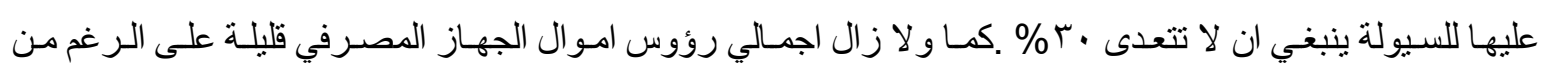


زيادتها اذ لا تزال تشكل بحدود ب٪ من الناتج المحلي الاجمالي و هذا يعكس تو اضع هيكلية الصناعة المصرفية في

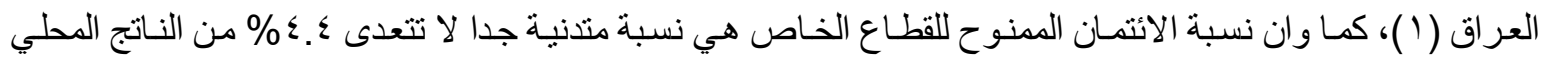

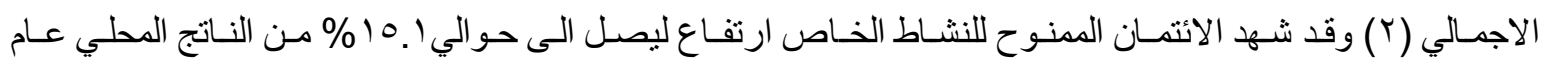

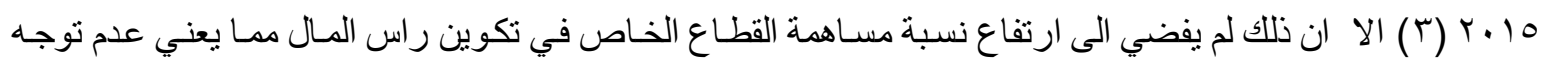

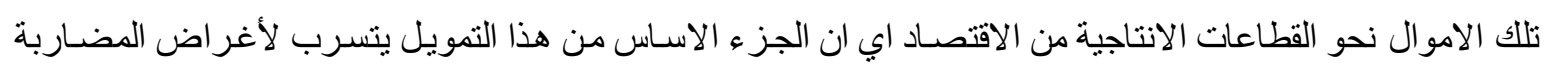

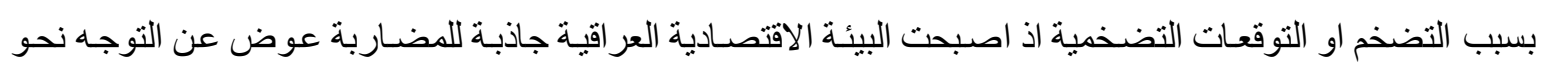

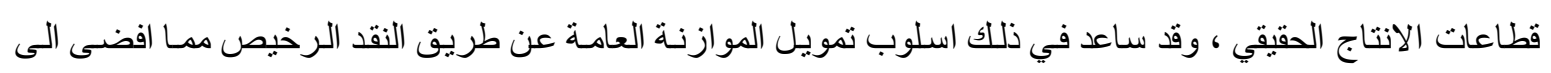

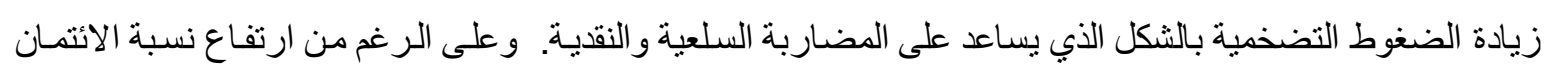
الا ان لا يزال يعبر بوضوح عن صغر او انخفاض سوق الائتمان في العراق وضعف النشاط التمويلي .

r - زيادة معدل الانتشـار والذي سبب ضعف عمليـات الوسـاطة المالية وضعف صـلابة الصناعة المصرفية في

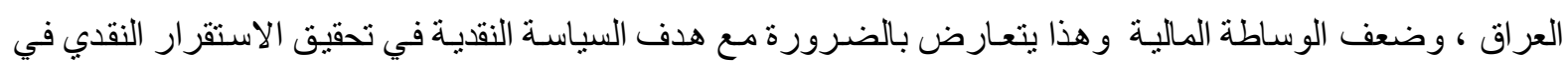

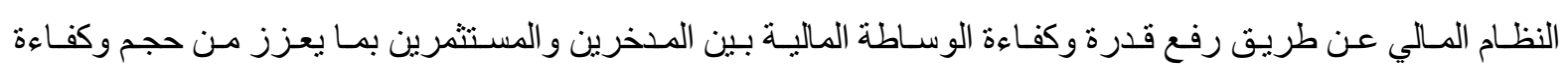
الاستثمار .

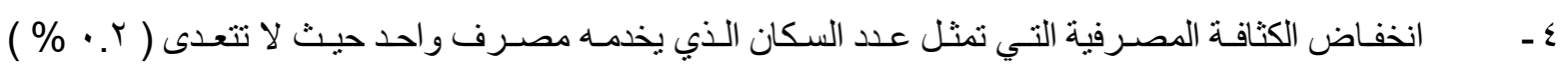

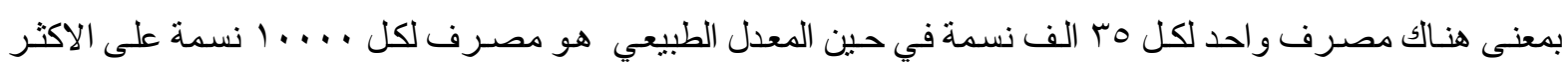

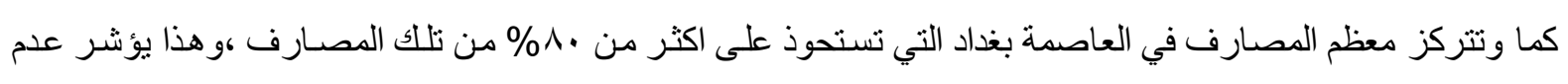

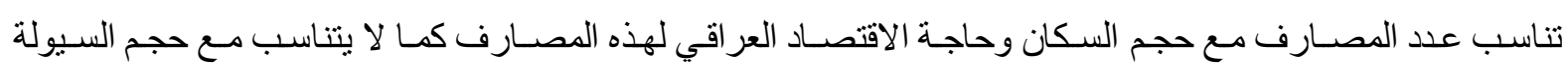

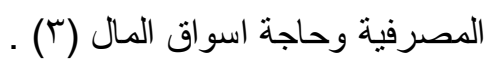
0 - كذلك انخفاض نسبة كفاية راس المال في المصسارف الحكومي وتدني الملائنة المصرفية (وهو عبارة عن راس المال الاساس والثانوي منسوب الى انواع المخاطر المختلفة (مخاطر الايتمان + مخاطر السوق + مخاطر التشغيل).

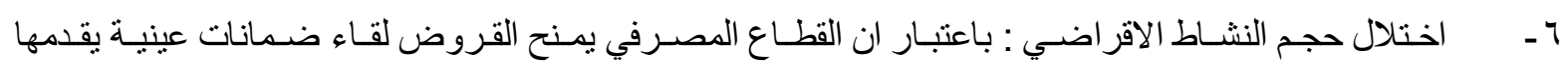
المقترض ممـا يبعد النسبة العظمى من المستثمرين عن الحصـول على القروض بسبب عدم تو افر نلك الضمانات للديهم

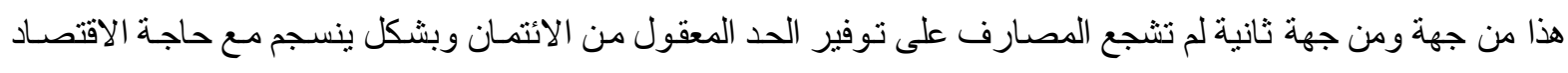

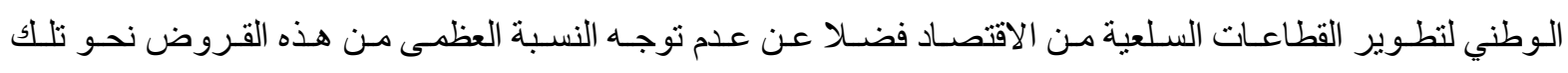

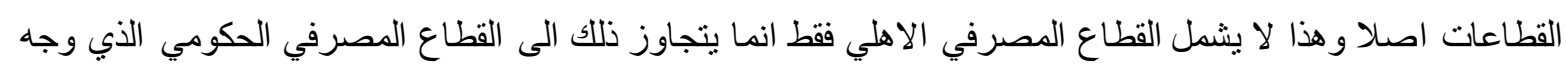

اخذت الارقام من البنك المركزي العراقي ، الدديرية العامة للاحصاء والبحوث ، قسم الاحصاءات النقاية والمالية ، بيانات عامي .

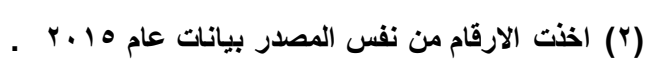

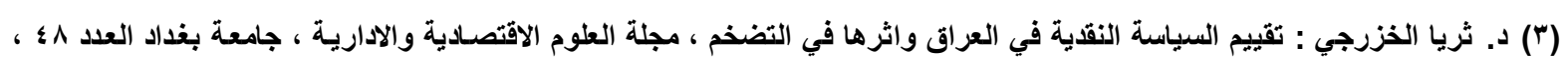

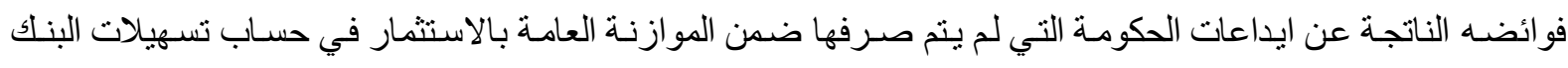

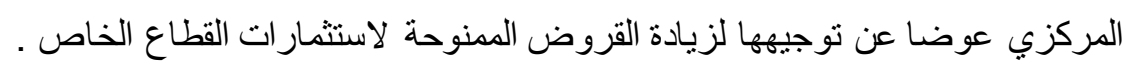

\section{- Y YA.}


انن و على وفق اعتمـاد العـراق سياسـة الكبح المـالي كجز ء مـن السياسـة الاقتصـادية التي استنـت الى التخطيط

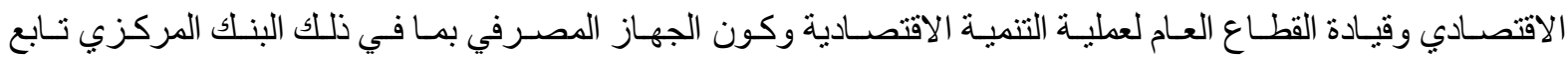

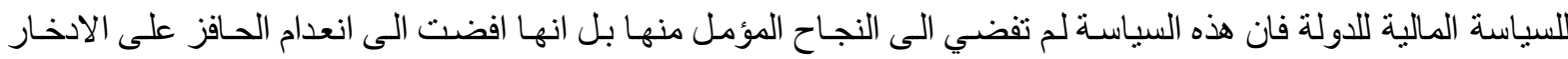
نتيجة انخفاض سعر الفائدة الحقيقي والدور الضعيف للوسـاطة المالية وقدرتها في نعبئة المدخرات ومن ثم التخصيص

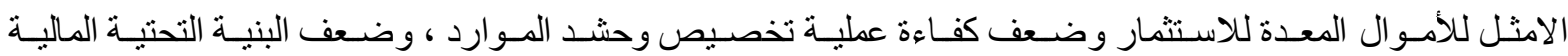
و المصـرفية ، و عدم تـو افر اي انوع مـن الافصـاح المـالي و المحاسبي ، فضــلا عن انخفـاض القدرة على ادارة السياســة

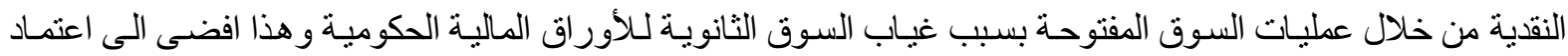

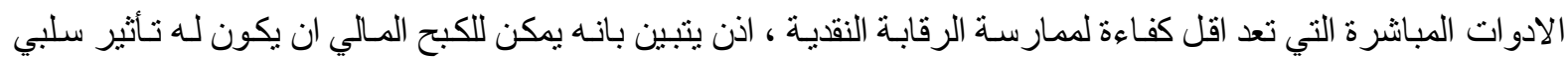

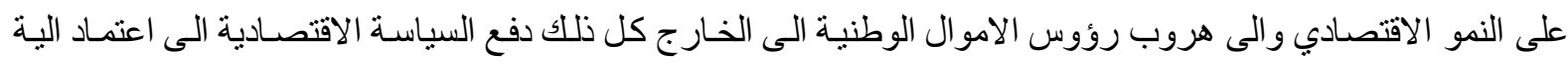

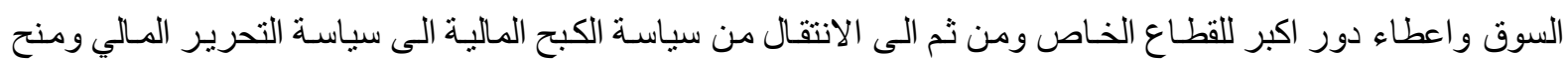
البنك المركزي الاستقلالية وازالة كافة الكوابح التي كانت معتمدة في المرحلة السابقة والعمل على :

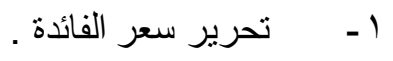

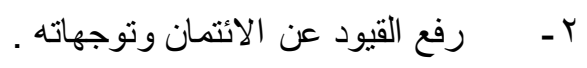

$$
\begin{aligned}
& \text { r- اطلاق حرية المصارف في تحديد نسبة الاحتباطي القانوني . } \\
& \text { ع ـتحرير رأس المال و اطلاق حرية حركتة . }
\end{aligned}
$$

هـاطلاق حرية التحويل الخارجي عدا تلك المتعلقة بتهريب رؤوس الاموال و وغسيل الاموال .

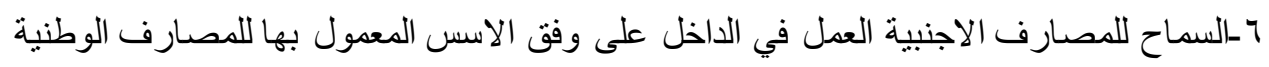
Vتعويم وتحرير سعر الصرف وان يحدد على وفق الية السوق وبأثر اف البنك المركزي.

وعلى وفق هذه الاجر اءات تسعى الدولة عن طريق التحرير المالي تحقيق المنافع الاتية ( ):

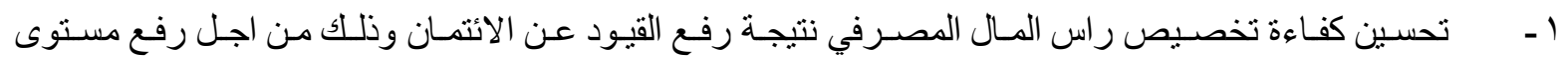

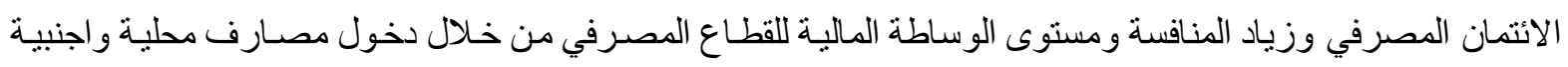

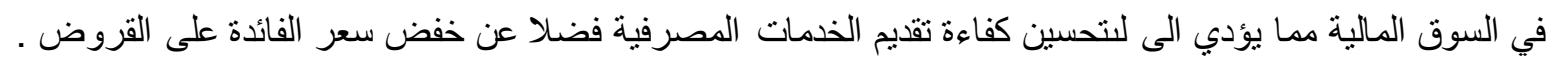

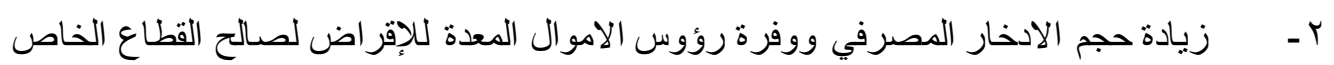
مما يؤدي الى رفع مستوى النطور المالي ومن ثم دعم النمو الاقتصادي.

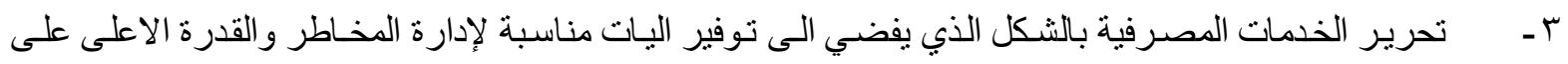
استيعاب الصدمات .

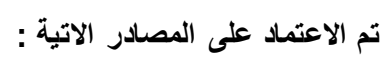

- حيدر بن عبدالرضا اللوتي : القطاع المصرفي في دول مجلس التعاون الظيجي في ظل تحرير الخدمات المالية ، مجلة المركزي العدد ؟ ،

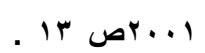

Roland C : Banking Sector Liberalization In India ,A springer Company Heidelberg ,Germany,pp180$181,2008$. 
ع - تطوير العمل المصرفي وتتويع الخدمات المصرفية وتطوير المهارات الاداريـة بالاعتمـاد على الكفاءات العلميـة المحلية و الاجنبية في مجال العمل المصرفي ممـا يؤدي الى تحسن خدمات الوسـاطة الماليـة وخلق المنـاخ الملائم لزيـادة

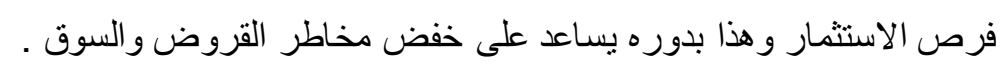

ـ ـ ستودي المنافسة الى انسحاب المصارف غير القادرة على التحسن و الاستمر ار في السوق ممـا بسر ع من عملية

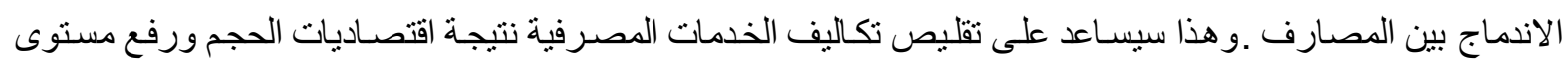

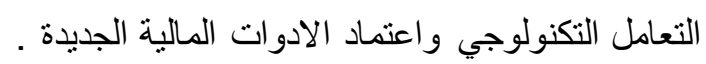

و على اية حال تسعى الدولة من خلال سياسة التحرير المـالي الى زيسادة حجم الانخار المحلي و التخصبص الامثل

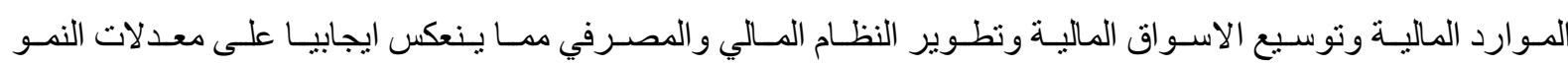

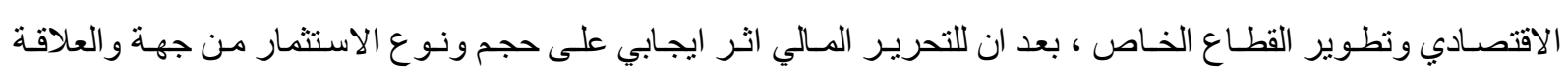

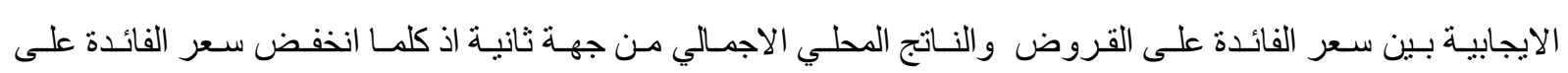

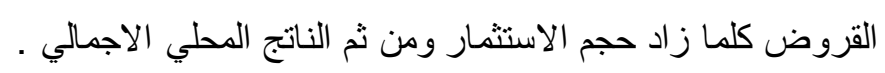
الا ان السؤال الذبي يطـرح نفسـة هنـا هو هل ان هذه السياسـة افضت الى تحقيق النتـائج المتوخـاة منهـا هذا مـا سنحاول تبيانه من خلال المبحث الثناني .

المبحث الثاني :دور السياسة النقدية والبنك المركزي في التاثير في بعض المتغيرات الاتتصادية وفي تهقيق

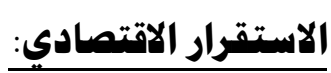

من المعلوم ان من اهم اهداف السياسـة النقدية تحقيق الاستقرار النقدي والمحافظة على استقرار سعر صرف

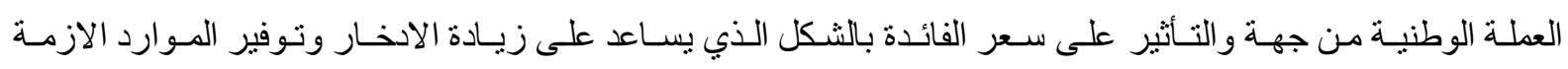
للاستثمار من جهة ثانية مما ينبغي معهد على البنك المركزي المحافظة على مناسيب السيولة وعرض وضل النقد في الاقتصـاد

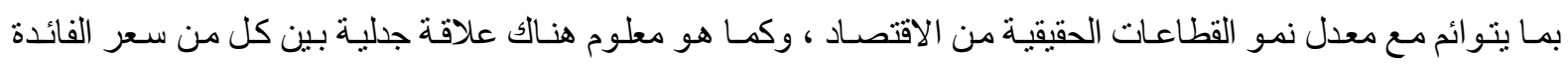

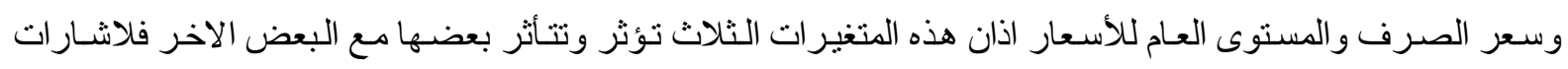

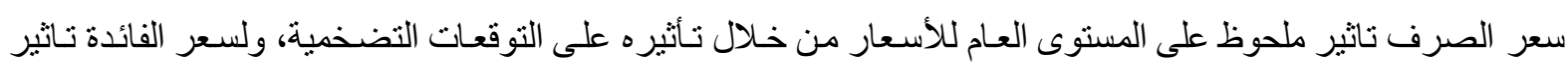

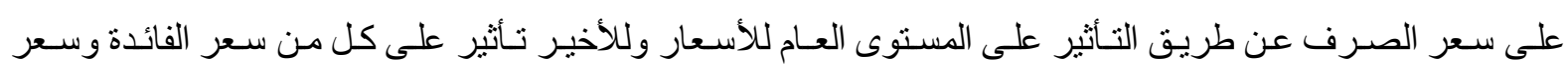

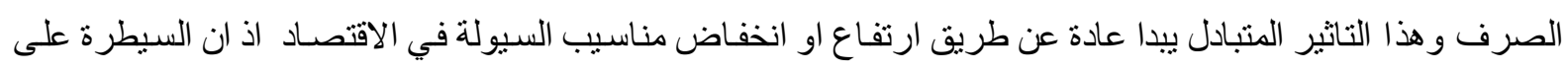

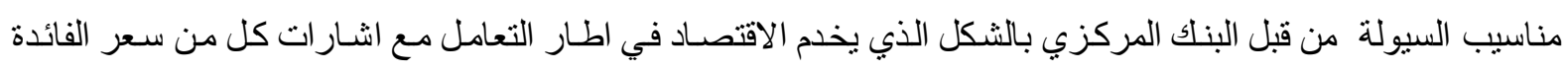
وسعر الصرف وتوجيهها بما يحقق الاستقرار في قيمة العطلة .

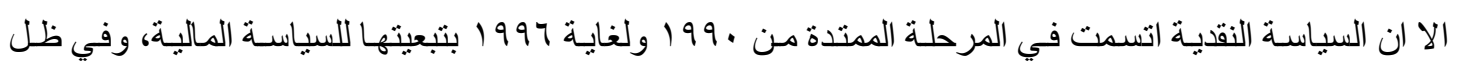

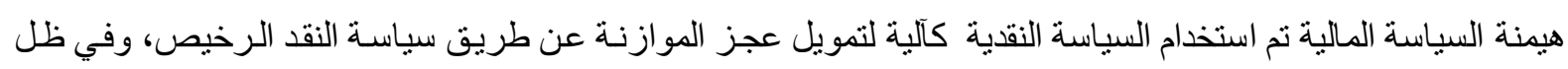

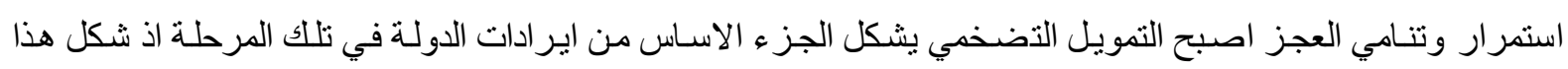

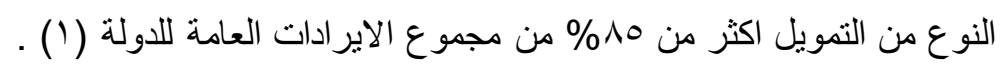


وعلى وفق هذه السياسـة فقدت السياسـة النقديـة قدرنها على التأثير لاسيما في السيطرة على مناسيب السيولة

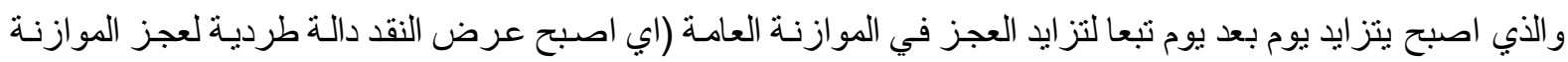

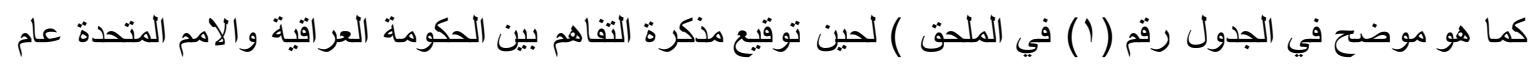
1997 ، ، بدا التخلي التدريجي عن سياسـة النقد الرخيص باستاناف تصدير النفط العر اقي تبعـا لمبدا النفط مقابل

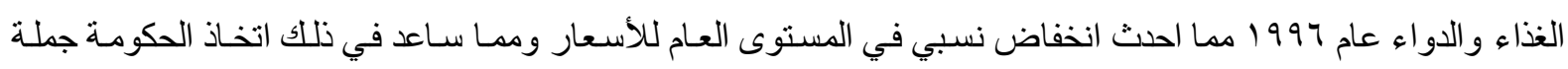
من الاجر اءات لتقليص النفقات العامة من جهة وزيادة اير ادات الدولة عن طريق زيادة الضرائب و الرسوم من جهه ثنانية و هذا افضى الى الغـاء الاعفاءات الضـريبية التي كانت سـائدة واز الذة الدعم عن بعض اسعار السـلع ممـا سـاعد على تقليل

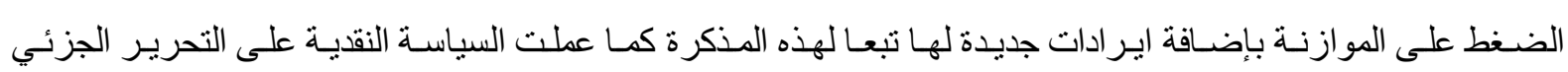

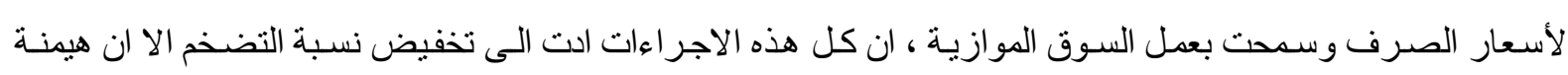

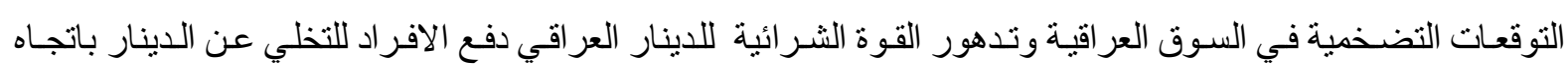
الدو لار و الموجودات الاخرى ذات القيمة المستقرة لا سيما الموجودات الحقيقية . و على ايـة حسال لـم يكن ظهور التضخم في العراق وليد هذه المرحلـة انمـاظهر في اواسط السبعينات من القرن

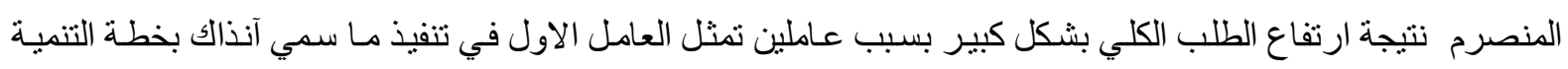

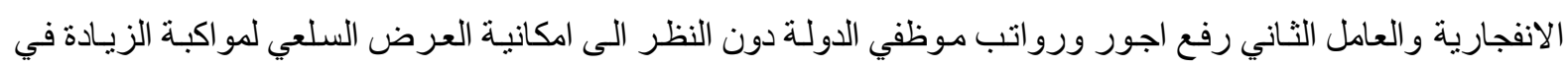

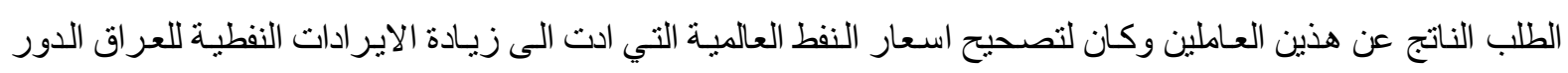

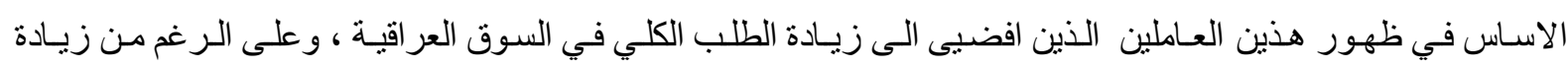

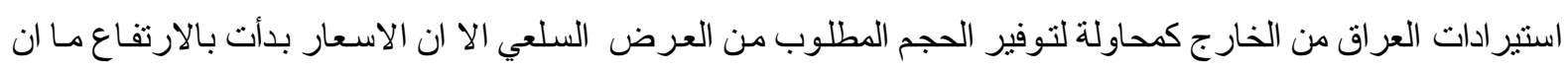

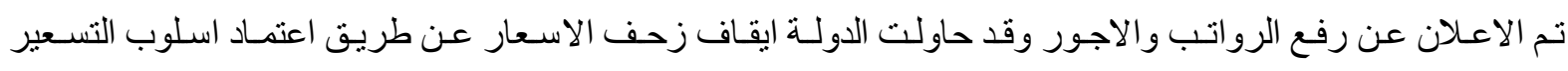

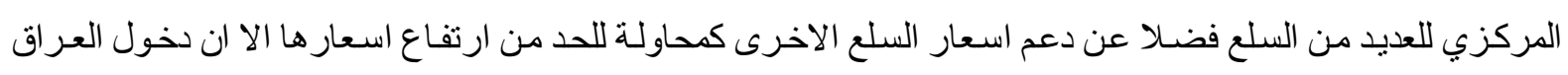
حرب الخليج الاولى مـن جهـه وتحويـل مـوارد الاقتصـاد باتجـاه دعم اقتصــاد الحرب مـن جهـة ثنانيـه والتوقف الجزئسي

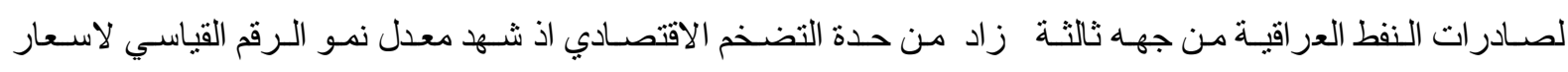

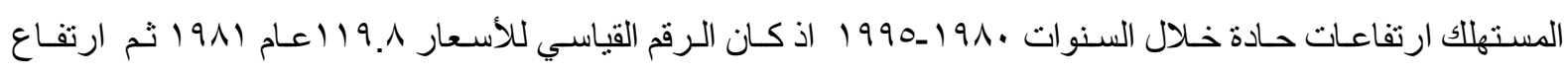

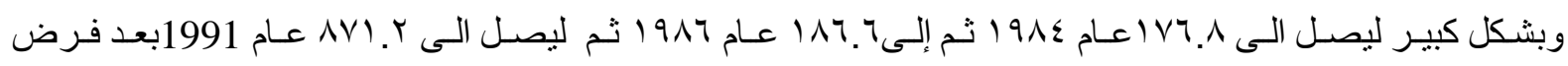

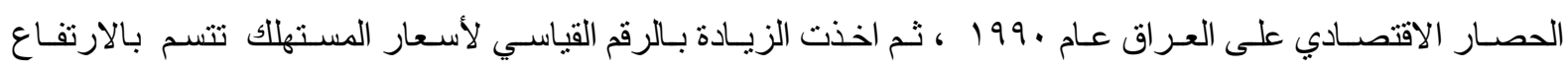
بمعدلات عالية ليصل إلى (4924.7) عام (1993) وبمعدل تغير سنوي بلغ (207.6\%) ثم إلى 37078 3ـام (1994)

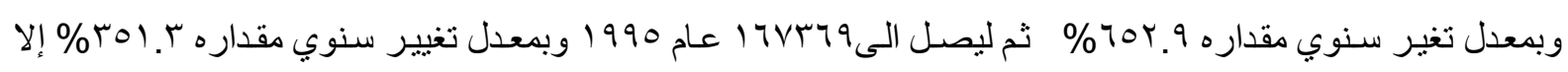

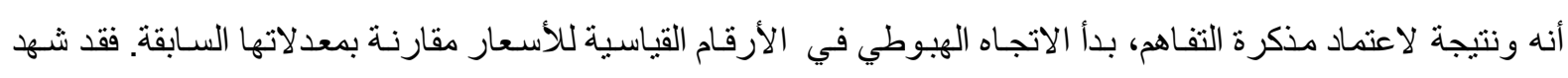

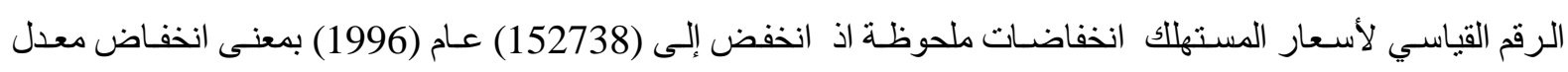

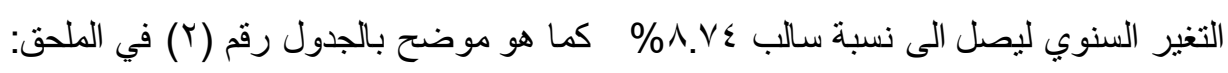

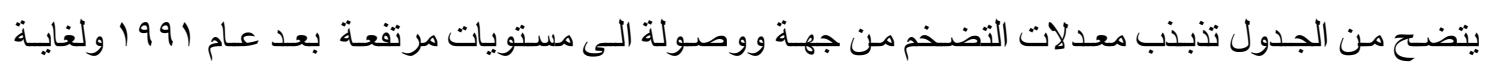

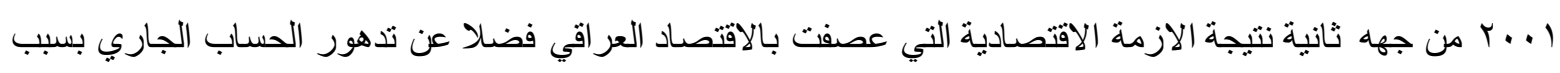


انخفاض تصدير النفطـو هذا دفع الحكومـة آنذاك الـى الاعتمـاد على الاصـدار النقدي لتمويل الموازنـة العامـة عن طريـق

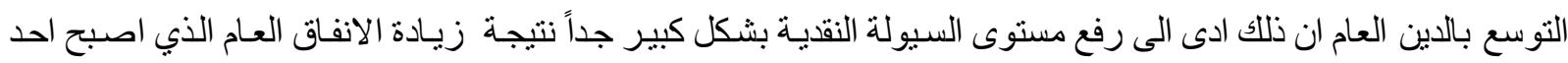

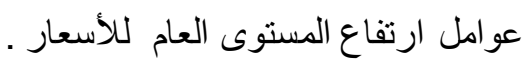

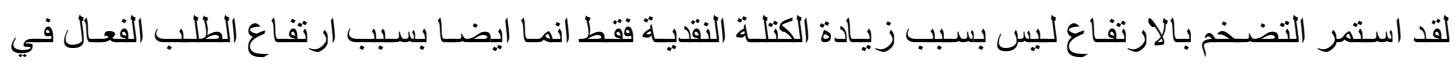

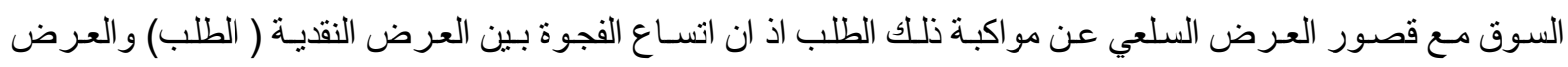

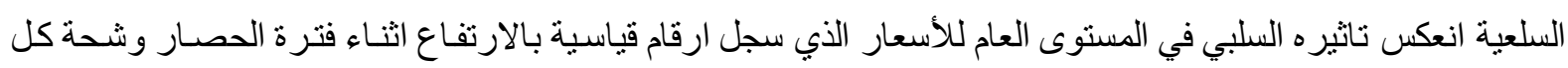

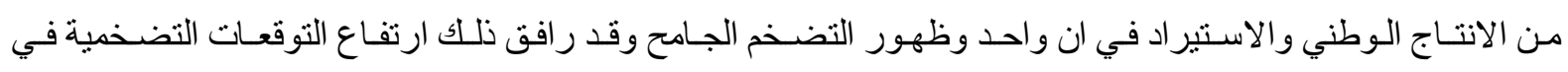

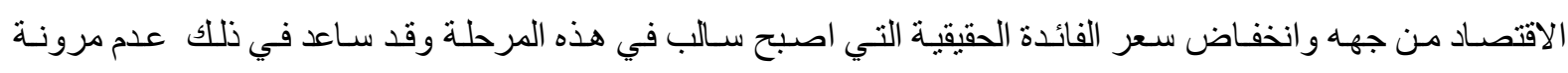

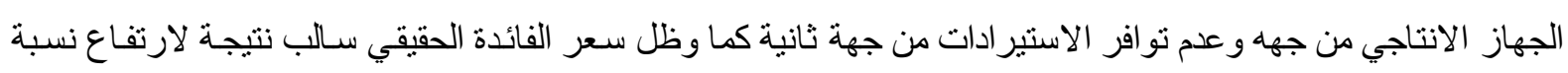

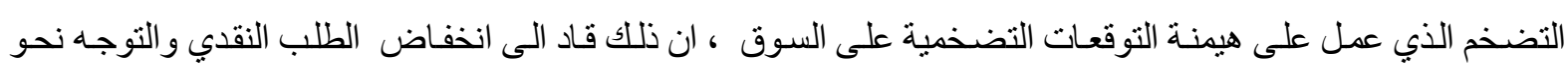

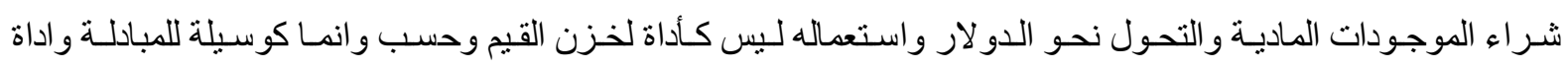

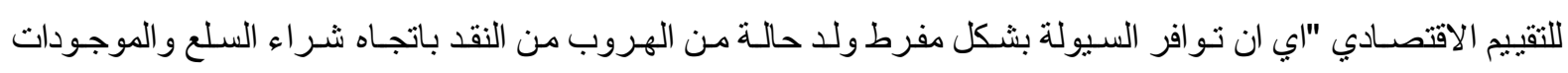

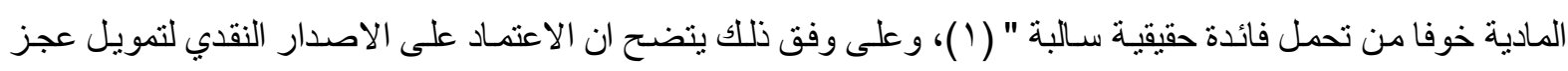

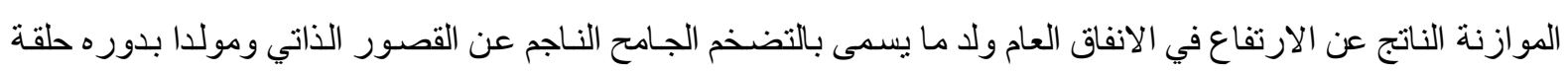

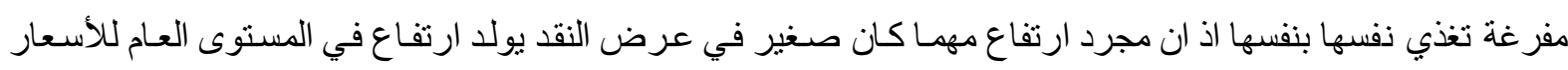



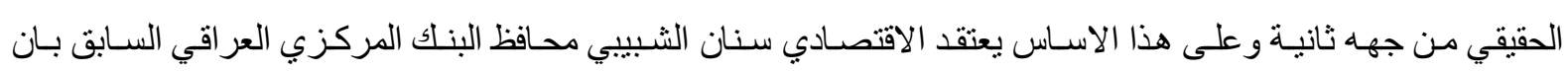

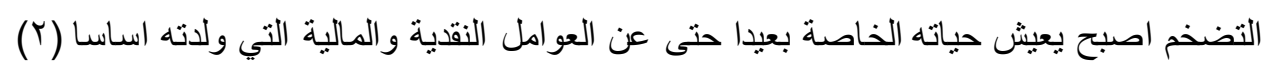
سـعر الصـرف : شـهدت هذه المرحلـة تدهور سـعر الصـرف وعدم استقراره نتيجـة زيـادة الطلب على العملـة الاجنبية لتغطية الاستير ادات من حهة وزيادة المضاربة وتهريب العملة الاجنبيـة لتغطية مـا سمي بالاستير اد دون تحويل

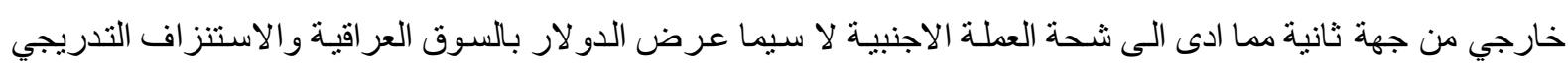

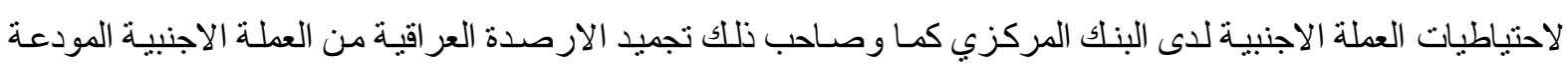

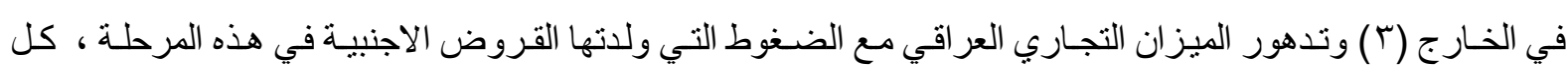

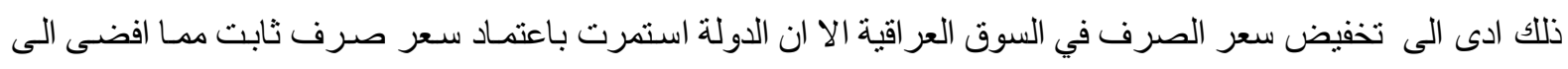
ظهور اسواق موازيـة للصرف و اتسـاع الفجوة بين هذه الاسـعار وسعر الصـرف الرسمي بل وكانت هنـالك عدة اسعار

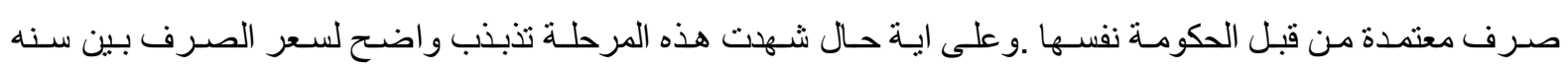

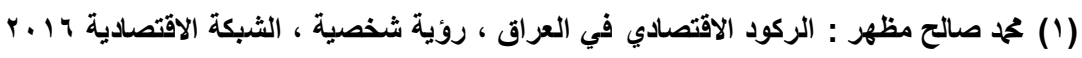

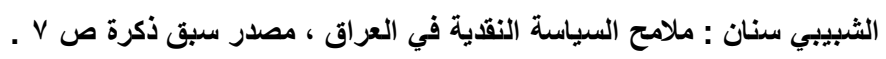

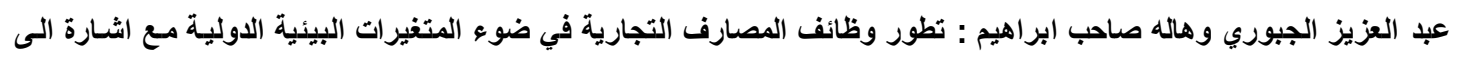

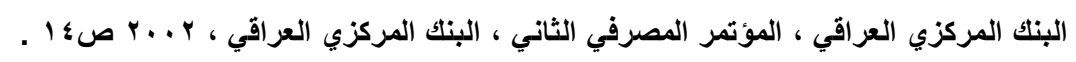




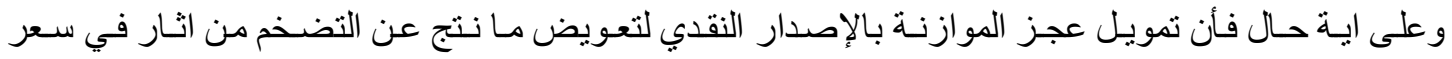

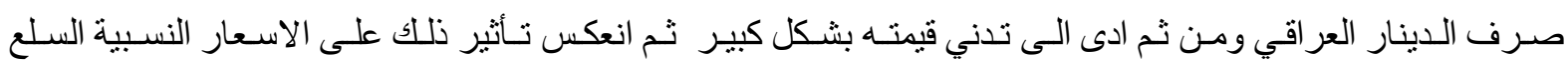



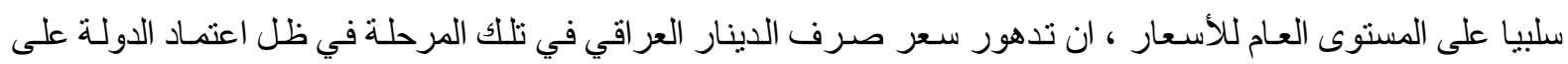

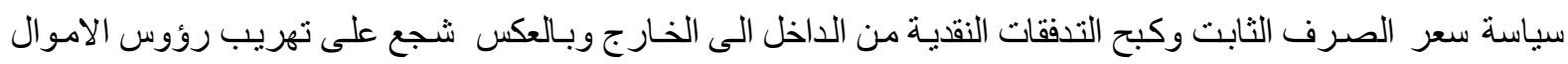

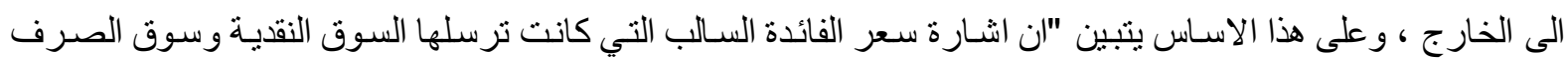

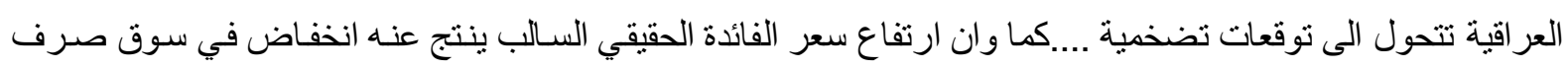

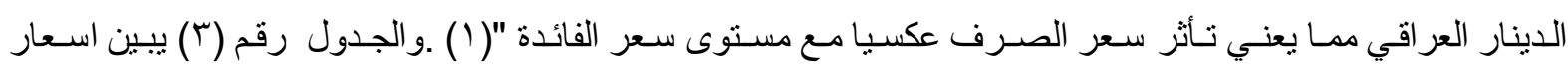
الصرف خلال هذه المدة : مديني

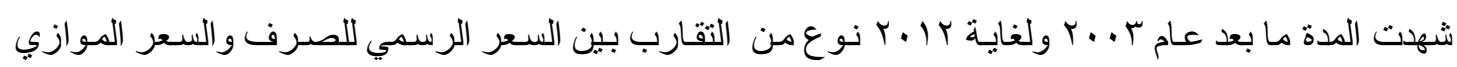

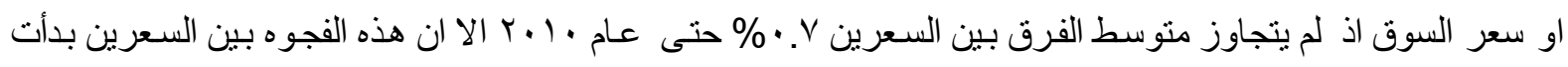

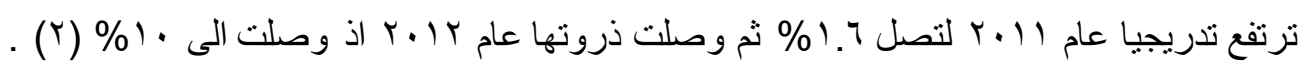
سعر الفائدة : فثنل البنك المركزي في استخدام اداة سعر الفائدة في تحقيق الاهداف المبتغـاة من السياسـة النقديـة

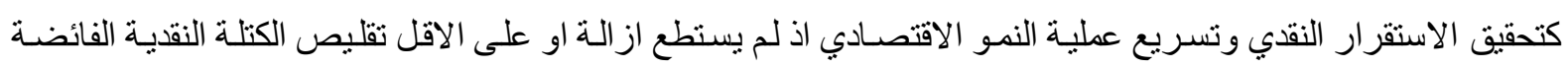

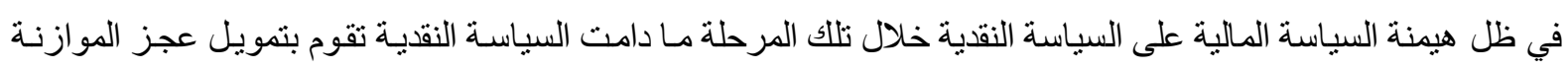

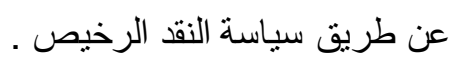

لقد عمدت السياسـة النقدية الى التحديد الاداري لأسعار الفائدة كمحاولة منها لتشجيع الادخـار ، ولم تكتفي بذلك

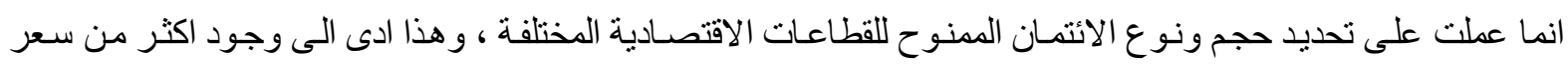

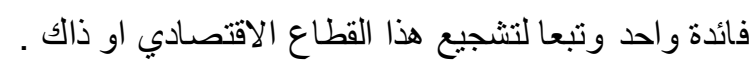
حاولت السياسة النقدية امتصـاص او تقليل الارتفاع الحساد في السيولة النقديـة عن طريق رفع سعر الفائدة اذ تم

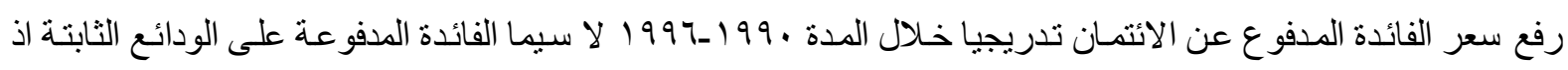

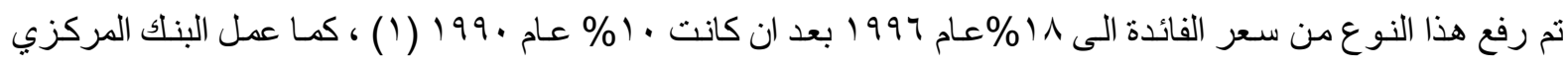

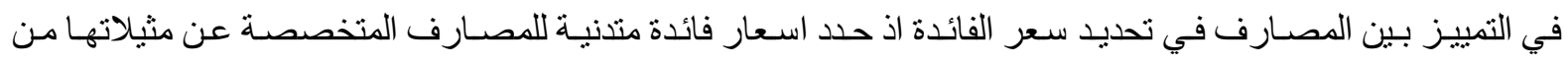
اسعار الفائدة في المصـارف التجاريـة ، وكمحاولـة منـه لتخفيض كلفـة الدين العـام حدد سـعر الفائدة في سـندات الخزينـة

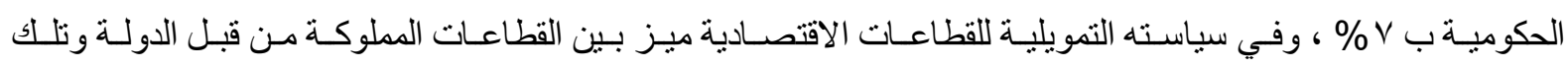

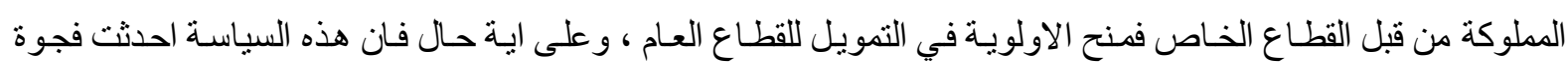

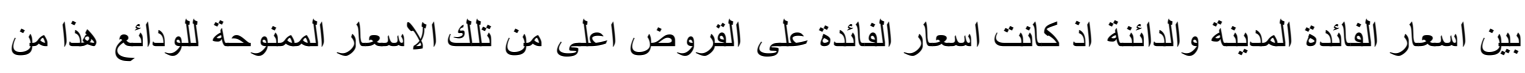

محم صالح مظهر : الركود الاقتصادي في العراق ،مصدر سبق ذكره .

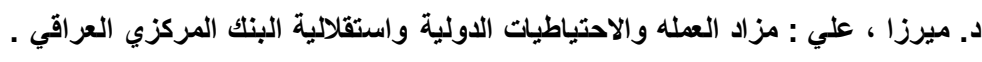

Http:// www.mees.comlen/articLe/6978-examining-the-cbi-iraq-government-conflict-a-focus-on-forex الثماع ، همام : الانتمان المصرفي في العراق الواقع و المتطلبات ، المؤتومر العلمي الثالث لقسم 
جهة ومن جهـة ثانيـة اصبحت اسـعار الفائدة المحددة لا تنسجم بـاب شكل من الاشكال مـع الادعـاء بتشـيع

الاستثمار اذ انها تفوق العو ائد المتوقعة من الاستثمار في السوق العر اقية وعلى هذا الاسـاس شكلت اسعار الفائدة عامل لهاهل

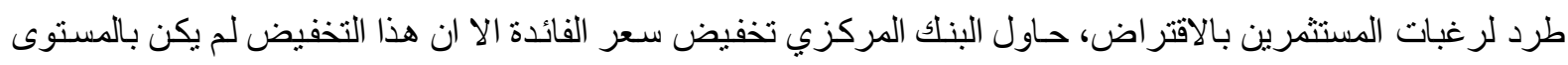

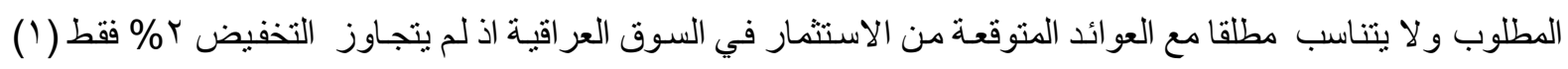

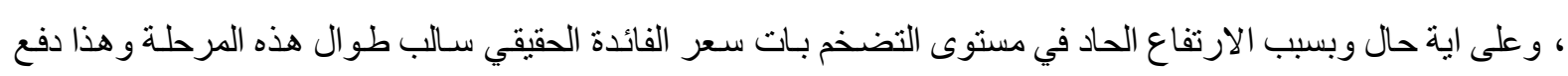

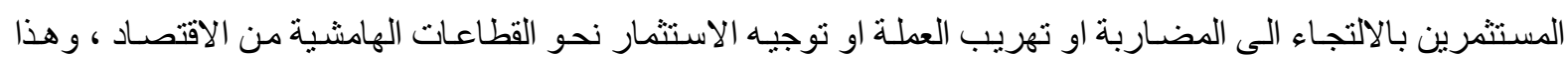
يوشر عجز السياسة النقدية عن خلق الظروف الملائمة لتشجيع النمو الاقتصادي .

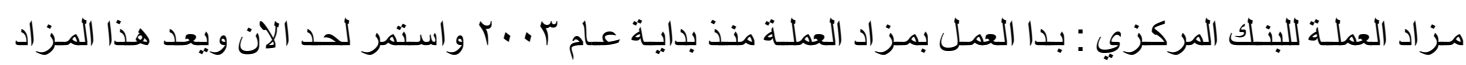

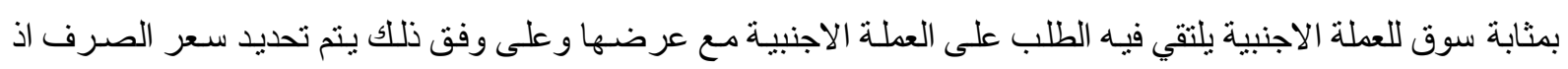

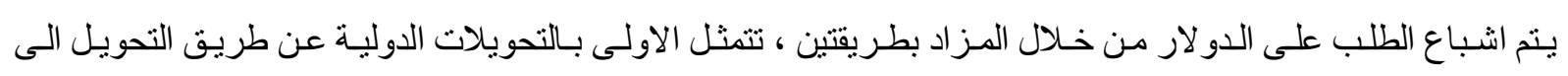

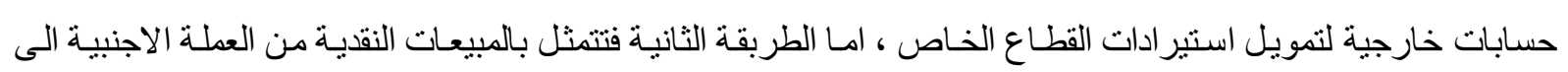
المصارف لتمويل باقي الاحتياجات من العملة الاجنبية كتمويل السفر الى الخارج او العلاج او التعليم او الإيفادان....الخ . .

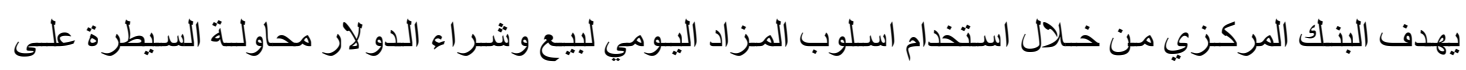

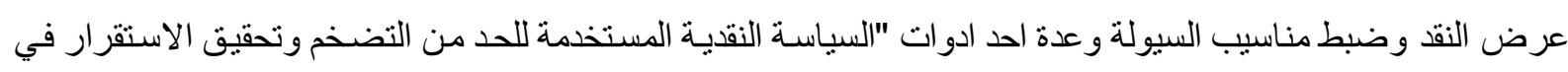
المستوى العام للاسعار وتلبية طلب المصارف و المواطنين على الدو لار" ( (؟). و ولية يعد المز اد احد الوسائل المهمة لسحب العملة الوطنية الفائضـة بالسوق عن طريق تبديل الدينار بالدو لار فضـا عن

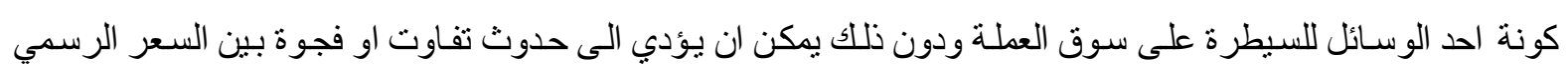

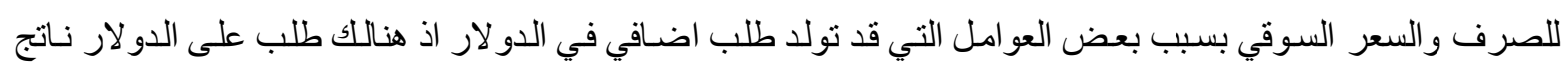

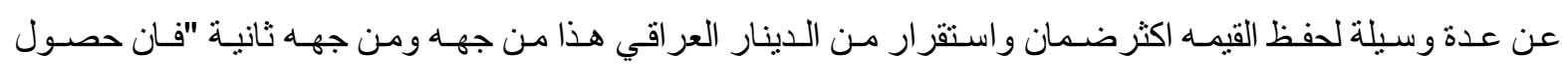

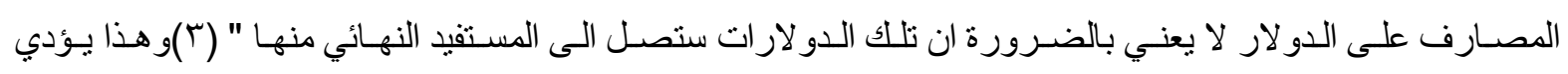

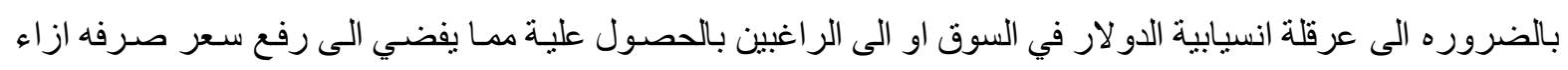

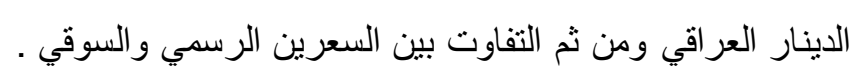

اهداف مزاد العملة :يهدف مزاد العملة الى تحقيق جملة اهداف بعدة جزء من السياسة النقدية وعلى النحو الاتي ( ) : 1 - ت تحقيق استقرار سعر صرف الدينار العراقي ازاء الدولار من خلال تحقيق التوازن في سوق الصرف اي التوازن بين عرض الدولار والطلب علية .

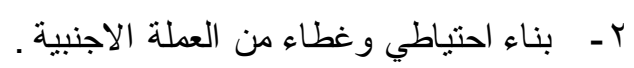

للاستزادة راجع :سامي فاضل عطو : تطور هيكل القطاع المسالي وادوات السياسة النقاية والمصرفية لتفعيل الاقتصاد العراقي ،

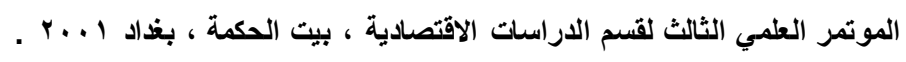

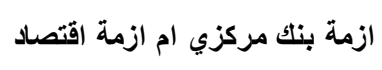

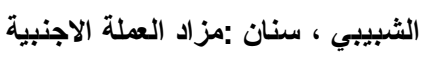


r - تنشيط السوق الثانوية عن طريق تطوير عمليات بيع وشر اء العملة من قبل المصارف التجارية . ع - زيادة الترايط بين سعر الصرف وسعر الفائدة . ـ - اعادة تنسيق اعمق لعمليات التحويل الخارجي .

7 - - سب السيولة النقدية الفائضـه للاينار العر اقي من السوق ممـا يؤدي الـى التـاثير الايجـابي على خفض التضـخم الاقتصادي .

V- - اشباع الطلب على الدو لار في السوق بسـر مناسب مـا دام الحجم المتز ايد مـن العملـة الاجنبيـة توفر المرونــة والاطمئنان في مقابل الطلب .

الاسلوب المتبع لاشتراك في المز اد : تبدا عملية الحصول على العملة الاجنبية عن طريق المزاد عند قيام

$$
\text { الفرد بتقديم طلب للاستيراد ( او لاي اغراض اخرى مسموح بها للحصول على الدولار ) }
$$

الى المصـرف التجـاري الذي يتوجب عليه تدقيق هذا الطلب بشكل تفصيلي ، في حين يقوم البنك المركزي

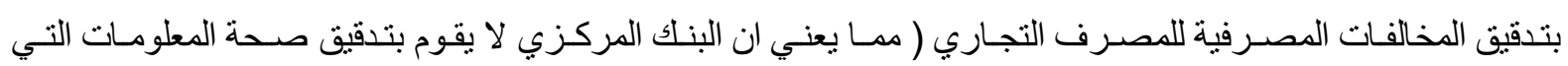
يقدمها صاحب الطلب انما يعتمد على تدقيق المصرف التجاري وبغض النظر عن صحة التدقيق )، وبعد ان بنسلم البنك

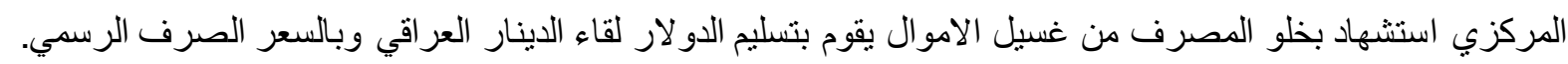
ان عملية منح الدو لار لقاء الدينار تبعـا لمز اد العملة شـابها العديد من الاخطساء والمخالفات بشكل متعمد او غير

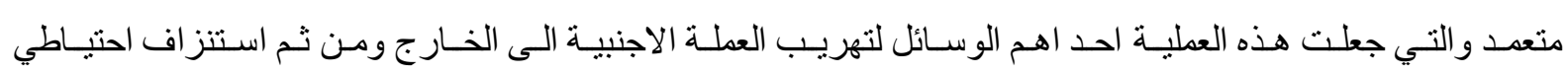

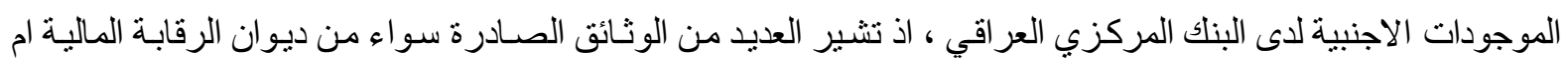

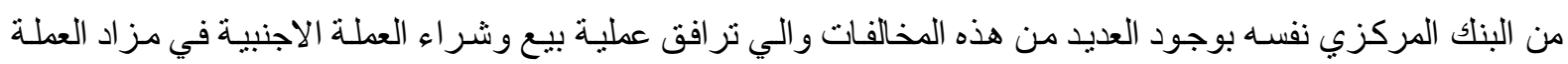

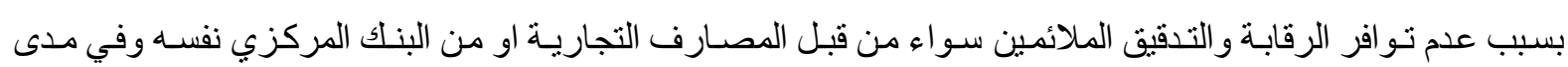

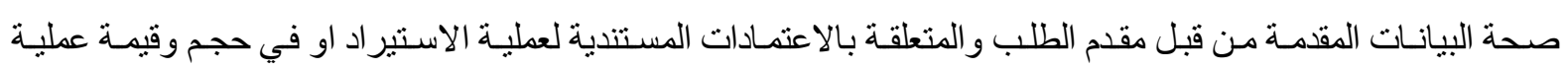

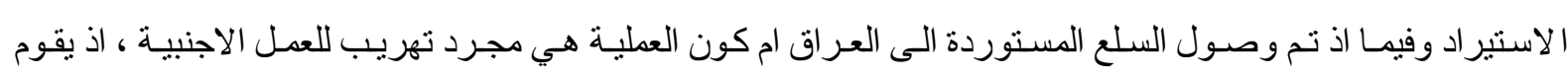

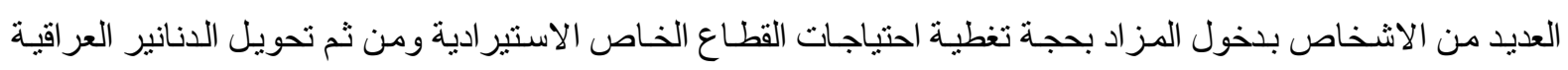

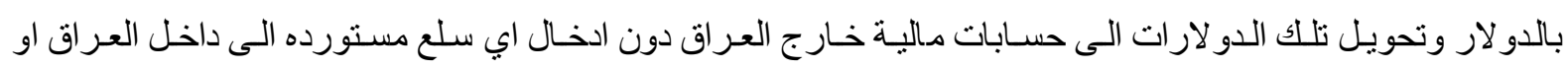

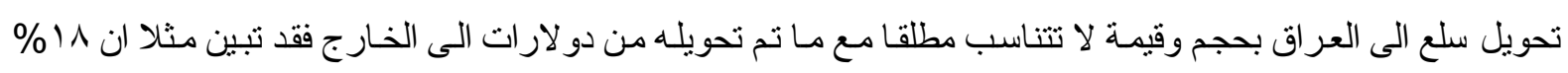

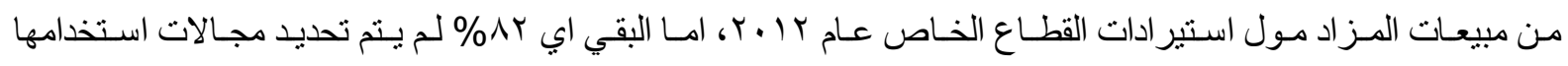

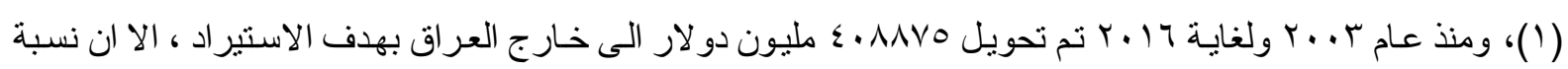
الاستيرادات الفعلية لم تتجاوز 0 \%\%من هذا المبلغ اي لم تتجاوز 


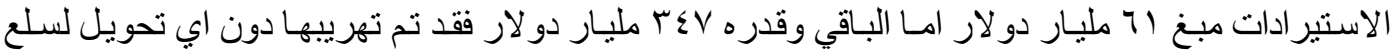

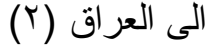

من وجهه نظر البنك المركزي ، ان البنك لا يتحمل اي مسؤلية في هذا الشـان ويعتقد الدكتور سنان الثبيبي محافظ البنك المركزي السـابق ينبغي لا يـلام البنك حول تلـلك العمليات لانه لا يتابع عملية الاستيراد " باعتبار ان ارقام الاستيراد النهائية تقدم الى الجهات الاحصائية .

www.iraq. 5050.com . مركز الروابط للار اسات الاستراتيجية والسياسية )

و هذا عذر غير مقبول لا سيما ان البنك المركزي نفسـه يعترف بوجود مثل هذا التهريب للعملة الاجنبية تبعـا

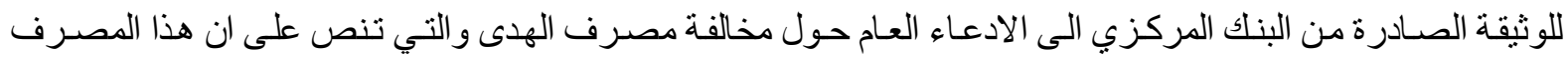

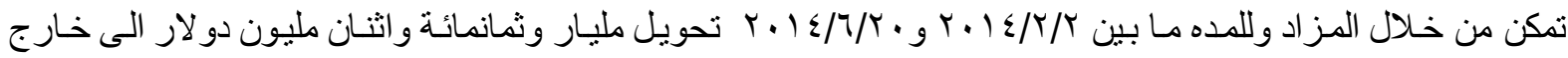
العراق من اجل الانفاق على الواردات وهذا لم يحثث (1) اي لم ينم استيراد اي سلعة لقاء هذا المبلغ . ان ذلك يعني ان البنك المركزي يحـاول ان يتتصل عن مسؤليته بهدار الارصدة الاجنبية للعراق والتي هي في

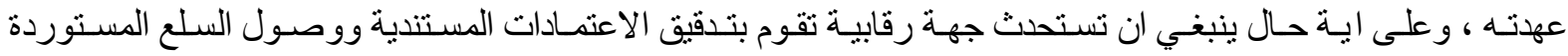

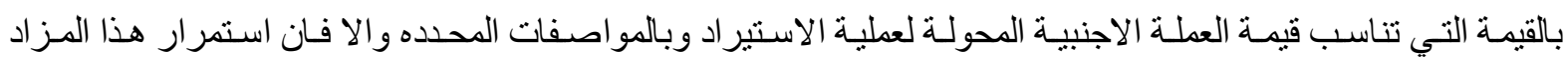
وبهذا الثنكل سيعني لا محال استنز اف رصيد العملات الاجنيبة لاى البناك المركزي وخسـارة العر اق للعمله الاجنبيه التي بحوزته .

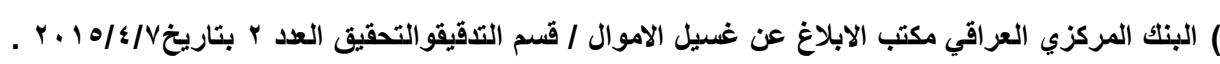

الاستنتتاجات والتوصويات

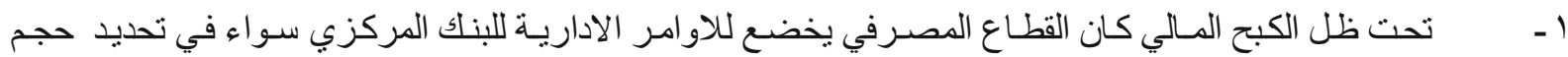
وتخصيص الائتمان وتحديد اسعار الفائدة ممـا شـوه من طبيعـة وعمل المصسارف وادى الى ضـعف كفاءة عمليـة تخصيص الموارد من جهة وارتفاع كلفة الوساطة المالية r - لم يكن سعر الفائده قادر في عكس درجة المخـاطر التي تتعرض لها العملية الائتمانية وقدرة هذه الاسعار في عكس الحالة الاقتصادية في الداخل والتناسب بين سعر الفائدة في الداخل وسعر الفائدة في الخارج . r - اتصفت الصناعة المصرفية بالعديد من الصفات و السمات السلبية كالخلل في بنية هيكل الصناعة المصرفية ، كاستحو اذ القطساع الحكومي على ( 9 \% ) مـن النشـاط واتصـاف الصناعة المصـرفية بشكل عـام بالسـيوله العاليـة مهـا يعكس تدني رغبة المصـارف في منح الايتمـان النقدي ممـا تسبب في انخفاض درجـة العمق المـالي ، اذ لا تتعدى نسبة

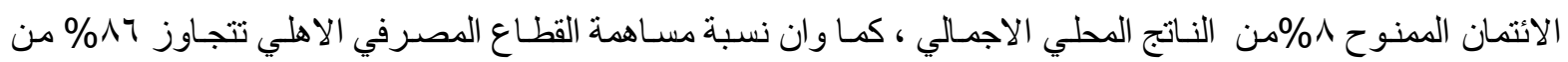

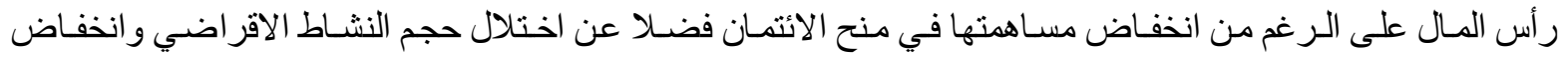
نسبة كفايـة راس المسال و لا تز ال السوق المصـرفية لا تشجع في توفير الحد الادنى المطلوب من منح الائتــان لتمويل 
القطاع الخاص ـ وارتفاع مستوى الانتشار الذي سبب ضعف عمليات الوسـاطة المالية اذ يبلغ الفرق بين الفائدة الممنوحـة للودائع والفائدة المستلمة من القروض ما بين 7ــ نقطة.

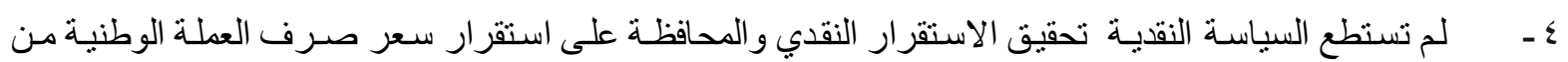

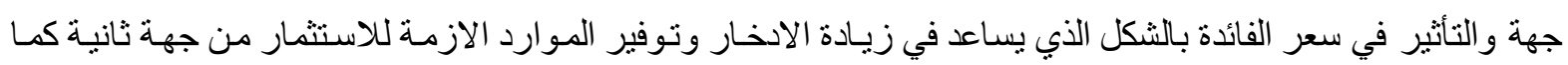

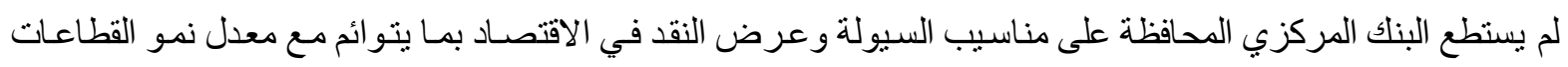

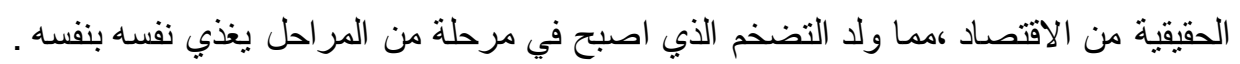

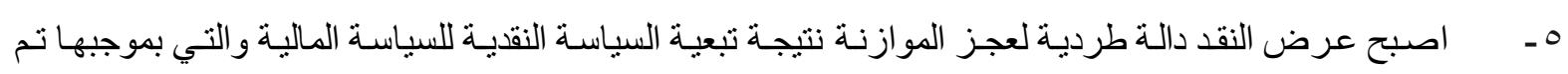
استخدام السياسة النقدية كآلية لتمويل عجز الموازنة عن طريق سياسة النقد الرخيص .

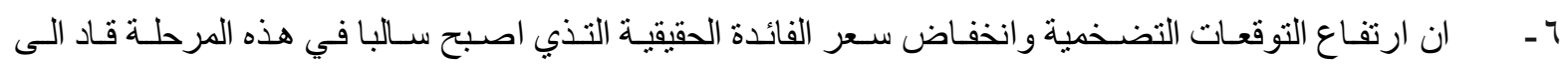
انخفاض الطلب النقدي والتوجه نحو شـراء الموجودات الماديـة والتحول نحو الدو لار واستعماله ليس كاداة لخزن القيم وحسب وانما كوسيلة للمبادلة واداة للتقييم .

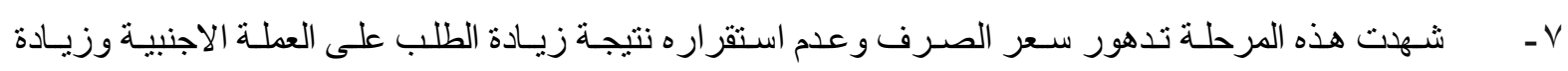

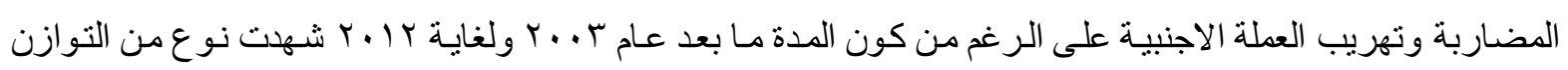

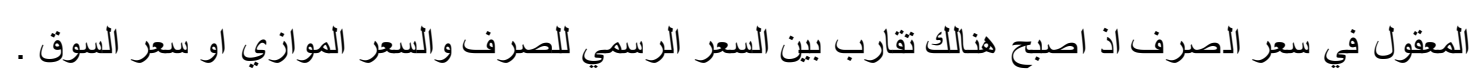

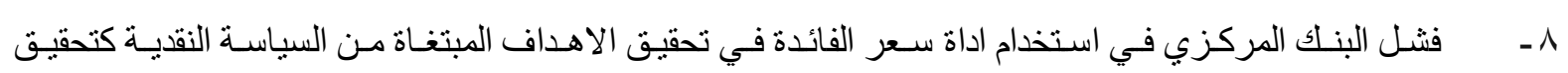
الاستقرار النقدي وتسريع عملية النمو الاقتصادي.

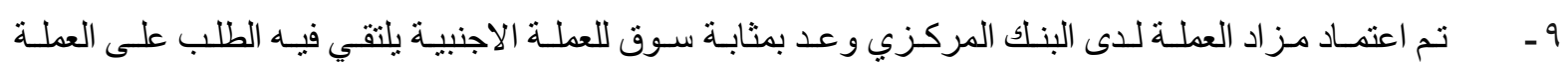

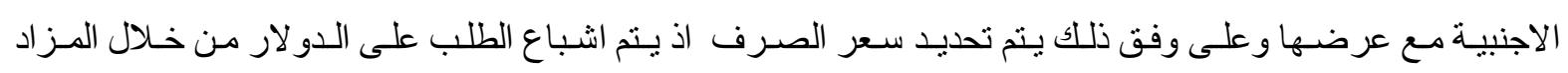

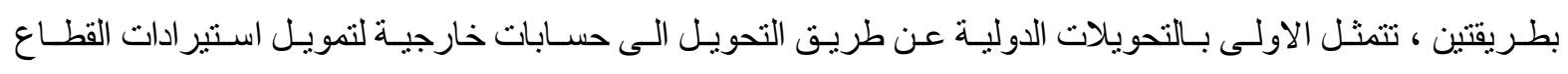

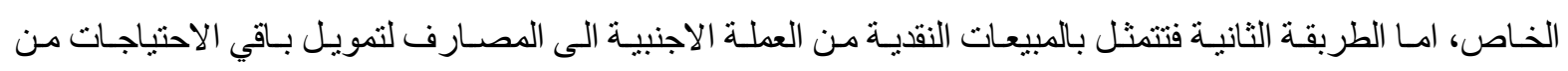
العملة الاجنبية كتمويل السفر الى الخارج او العلاج او التعليم .

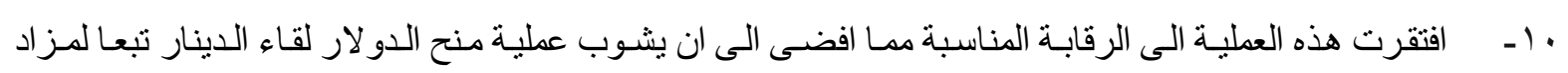

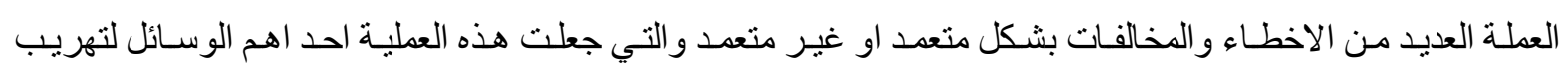
العملة الاجنية الى الخارج ومن ثم استنزاف احتياطي الموجودات الاجنبية لدى البنك المركزي العر اقي.

1 - اذا مـا اريد تحسين كفاءة عملية تخصيص الموارد من جهة وتقليص كلفة الوسـاطة الماليـة من جهة ثانيـة ينبغي اجر اء العديد من الاصـاحات في الصناعة المصرفية التي اتصفت بالعديد من الصفات والسمات السلبية كالخلل

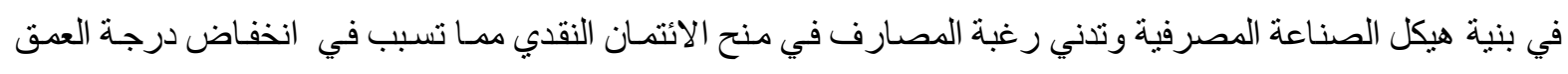

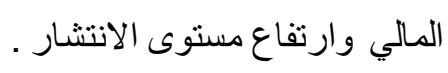
r - ضرورة ان يكون التعامل بين الحكومة والجهاز المصرفي تعامل تجاري بحت بعيدا عن اي ضغوط . 
ب - ضـرورة المحافظـة على اسـتقرار سـعر صـرف الـدينار العر اقي وتقليص الفجوة بـين سـره الرسمي وسـره السوقي وايجاد الاليات المناسبة لذلك بعيدا عن مزاد العملة الذ اصبح احد اهم وسائل تهريب العملة الاجنبية . ع- ايجاد اليات رقابية مناسبة خارجية وداخلية للجهاز المصرفي بالثكل الذي يضمن تحقيق الاهداف المنشودة منـه

http :/ /www.almasalah.com

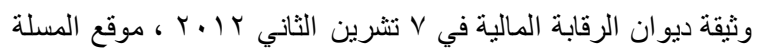

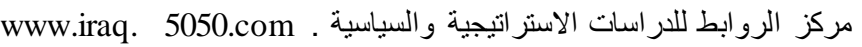

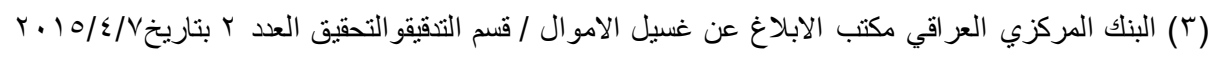

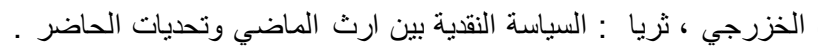

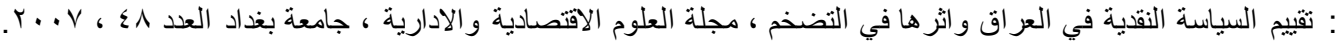

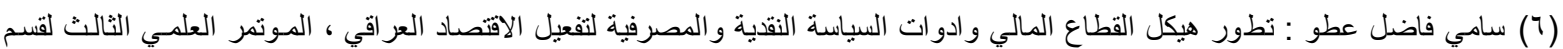

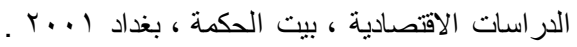

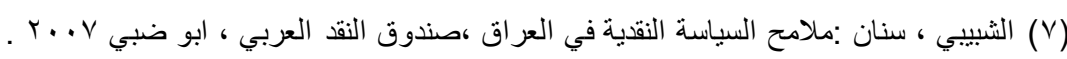
ازمة بنك مركزي ام ازمة اقتصاد :مزاد العملة الاجنبية لمعنية:

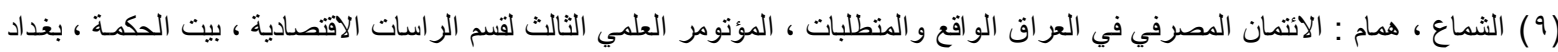

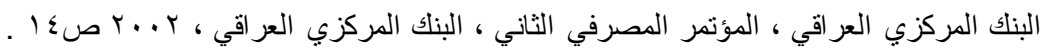

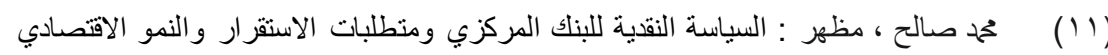

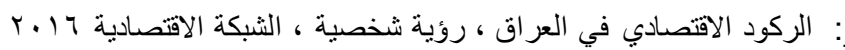

د. ميرزا ، علي : مز اد العمله والاحتياطيات الدولية واستقلالية البنك المركزي العر اقي .

Http:// www.mees.comlen/artic Le/6978-exa min ing-the-cbi-iraq-govern ment-conflict-a-focus-on-fore $x$

$$
\text { الملحق الاحصائي }
$$

جدول (1) يبين العلاقة الطردية بين عجز الموازنة وزيادة عرض النقد بملابين الدنانير

\begin{tabular}{|c|c|c|}
\hline عرض النق & عجز الموازنة & السنوات \\
\hline 10409.r & 0711 & 199. \\
\hline$r \leqslant 7 V$. & I וצף9.1 & 1991 \\
\hline \& & YVATO.A & 1994 \\
\hline Ат & $\leqslant 9907.7$ & 1994 \\
\hline rr人q. & IVTVOT.r & 199 \\
\hline$V .0 .7 \varepsilon$ & ᄉOrی.. & 1 \\
\hline 97.0 .1 & & \\
\hline
\end{tabular}

المصدر: وزارة المالية ، الدائرة الاقتصادية ن النشرة السنوية ؟ . . ب . 


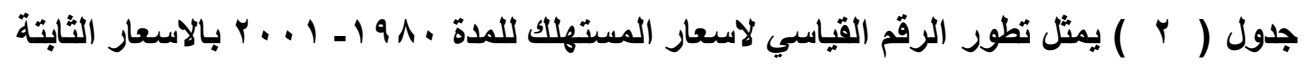

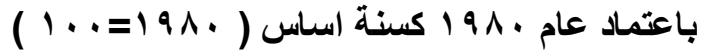

\begin{tabular}{|c|c|c|}
\hline & الرقم القياسي لاسعار المستههلك & السنة \\
\hline & 100 & 1980 \\
\hline & 119.8 & 1981 \\
\hline & 146.2 & 1982 \\
\hline & 163.7 & 1983 \\
\hline & 176.8 & 1984 \\
\hline & 184.3 & 1985 \\
\hline & 186.7 & 1986 \\
\hline & 212.8 & 1987 \\
\hline & 240 & 1988 \\
\hline & 274.4 & 1989 \\
\hline & 304.1 & 1990 \\
\hline & 871.2 & 1991 \\
\hline & 1600.9 & 1992 \\
\hline & 4924.7 & 1993 \\
\hline & 37078 & 1994 \\
\hline & 167367 & 1995 \\
\hline & 152738 & 1996 \\
\hline & 187335 & 1997 \\
\hline & 215005 & 1998 \\
\hline & 242046 & 1999 \\
\hline & 254949 & 2000 \\
\hline & 266743 & 2001 \\
\hline
\end{tabular}

المصدر : البنك المركزي العراقي ، المديرية العامة للاحصاء والبحوث ، تقارير سنوات مختلفة

\begin{tabular}{|c|c|c|c|}
\hline سعر الصرف & السنة & سعر صرف العملة & السنة \\
\hline $1 \leqslant V 1$ & $199 \mathrm{~V}$ & $\varepsilon$ & 199. \\
\hline 174. & 1991 & 1. & 1991 \\
\hline $19 V r$ & 1999 & $Y_{1}$ & 1994 \\
\hline 194. & $r \ldots$ & $V \varepsilon$ & 1994 \\
\hline 1994 & $r \ldots r$ & $\{07$ & 1995 \\
\hline $190 V$ & $r \ldots r$ & $17 V \leq$ & 1990 \\
\hline 1949 & $r \ldots r$ & $11 \mathrm{~V}$. & 1997 \\
\hline
\end{tabular}

